\title{
Adaptation in Pronoun Resolution: Evidence from Brazilian and European Portuguese
}

Eunice G. Fernandes ${ }^{a d l}$, Paula Luegi ${ }^{b}$, Eduardo Correa Soares ${ }^{c, a}$, Israel de la Fuente, $^{\text {ae2 }}$, and Barbara Hemforth ${ }^{\text {af }}$

${ }^{a}$ Université Paris Diderot-CNRS, Laboratoire de Linguistique Formelle,

Case Postale 7031 - 5, rue Thomas Mann - F-75205 Paris Cedex 13.

Tel.: (+33) (0)157275764

${ }^{b}$ University of Lisbon, Centro de Linguística

Faculdade de Letras, Alameda da Universidade, 1600-214, Lisboa.

Tel.: (+351) 2179200 00; Email: paulaluegi@,letras.ulisboa.pt

${ }^{c}$ Université Paris Diderot, CLILLAC-ARP, Centre de Linguistique Inter-langues, de Lexicologie, de Linguistique Anglaise et de Corpus, Case Postale 7002, 5 rue Thomas Mann, 75205 Paris Cedex 13

Tel.: (+33) (0)1 572757 64; Email: eduardo.correa@etu.univ-paris-diderot.fr

$d_{\text {Email: eunice.fernandes@paris7.jussieu.fr }}$

${ }^{e}$ Email: israel.delafuente@univ-lille3.fr

$f_{\text {Email: barbara.hemforth@linguist.univ-paris-diderot.fr }}$

${ }^{1}$ Eunice G. Fernandes is now at Department of Linguistics, University of Lisbon. 
ADAPTATION IN PRONOUN RESOLUTION

${ }^{2}$ Israel de la Fuente is now at UMR 8163 "Savoirs, Textes, Langage”, CNRS-Université de Lille 3.

Corresponding author: Eunice G. Fernandes, Department of Linguistics, University of Lisbon, Alameda da Universidade, 1600-214, Lisboa.

Email:fernandese@,campus.ul.pt

Word count: 15415 , abstract: 248

(C) 2018, American Psychological Association. This paper is not the copy of record and may not exactly replicate the final, authoritative version of the article. Please do not copy or cite without authors permission. The final article will be available, upon publication, via its DOI: $10.1037 / x \operatorname{lm0000569}$ 


\title{
Adaptation in Pronoun Resolution: Evidence from Brazilian and European Portuguese
}

\begin{abstract}
Previous research accounting for pronoun resolution as a problem of probabilistic inference has not explored the phenomenon of adaptation, whereby the processor constantly tracks and adapts, rationally, to changes in a statistical environment. We investigate whether Brazilian (BP) and European Portuguese (EP) speakers adapt to variations in the probability of occurrence of ambiguous overt and null pronouns, in two experiments assessing resolution towards subject and object referents. For each variety (BP, EP), participants were faced with either the same number of null and overt pronouns (equal distribution), or with an environment with fewer overt (than null) pronouns (unequal distribution). We find that the preference for interpreting overt pronouns as referring back to an object referent (objectbiased interpretation) is higher when there are fewer overt pronouns (i.e., in the unequal, relative to the equal distribution condition). This is especially the case for $\mathrm{BP}$, a variety with higher prior frequency and smaller object-biased interpretation of overt pronouns, suggesting that participants adapted incrementally and integrated prior statistical knowledge with the knowledge obtained in the experiment. We hypothesize that comprehenders adapted rationally, with the goal of maintaining, across variations in pronoun probability, the likelihood of subject and object referents. Our findings unify insights from research in pronoun resolution and in adaptation, and add to previous studies in both topics: They provide evidence for the influence of pronoun probability in pronoun resolution, and for an adaptation process whereby the language processor not only tracks statistical information, but uses it to make interpretational inferences.
\end{abstract}

Keywords: adaptation; pronoun resolution; probabilistic comprehension; ambiguity. 


\section{Introduction}

Adaptation is the process whereby comprehenders use statistical information to make probabilistic inferences. In the current study, we investigate how Brazilian and European Portuguese comprehenders adapt to the statistical patterns of an experimental environment testing ambiguous pronoun resolution, a process where inferences about the (conditional) probability of referents given pronominal forms must be made. These inferences combine information about both the occurrence of pronominal forms, and the occurrence of referents. We manipulate the relative frequency (probability) of overt and null pronouns that can corefer either with a subject or an object referent, in order to test two competing hypotheses: Either comprehenders maintain their resolution preferences constant (across variations in pronoun probability), and infer changes in the relative likelihood of references to subject and object referents, or they change their resolution preferences (given changes in pronoun probability) in order to maintain relatively constant the likelihood of references to subject and object referents. We provide evidence supporting the second hypothesis, suggesting that comprehenders rely on their beliefs about the (relative) probabilities of referents when they interpret ambiguous pronouns.

Substantial research has shown that less explicit or informative anaphoric forms ${ }^{i}$ (i.e., words that refer back to previously introduced referents) are more likely interpreted as coreferring with entities that are more "prominent" in discourse, whereas more explicit anaphors preferentially refer to less prominent entities. For example, in pro-drop languages, null pronouns (Ø) elicit an interpretation bias towards subject referents, whereas overt ones (s/he) show a preference for non-subject referents (e.g., Carminati, 2002; Filiaci, Sorace, \& Carreiras, 2013; see, for an equivalent relation in non-pro-drop languages, Kaiser \& 
Trueswell, 2008; Järvikivi, Van Gompel, Hyönä, \& Bertram, 2005; Gernsbacher \& Hargreaves, 1988; Fukumura \& van Gompel, 2015).

One potential factor determining the prominence of referents is their probability of being re-mentioned in the upcoming discourse ${ }^{\text {ii. }}$. For example, Arnold (2001) found that speakers more likely continued sentences such as Lisa gave the leftover pie to Brendan.../ Marguerite caught a cold from Eduardo two days before Christmas... with a reference to the goal (Brendan, Marguerite) compared to the source entity (Lisa, Eduardo), and used more pronouns (e.g., he/she) relative to repeated names (Brendan, Marguerite) in those continuations. Arnold $(2001,2008)$ proposed that the general higher likelihood of speakers to refer to goal referents makes these more prominent (accessible) and, as a consequence, more likely to be referred to using a less explicit form.

Further research proposed that the bias of the interpretation of a pronoun is affected by the probability of re-mentioning referents, as determined by the semantics of the verb of the sentence where those referents occur. For example, Rohde and Kehler (2014, Experiment 1) showed that comprehenders interpreted, in $90 \%$ of cases, the pronoun $\mathrm{He}$ as co-referring with the subject after sentences with subject-biased implicit causality verbs (i.e., verbs where the subject is causally implicated), such as in John infuriated Bill. He.... However, subject choices decreased to $60 \%$ when an object-biased implicit causality verb (i.e., where the object is causally implicated) was used, such as in John scolded Bill. He..., suggesting that comprehenders used their knowledge about the higher likelihood of subject and object referents to be re-mentioned after sentences with subject-biased and object-biased implicit causality verbs, respectively. The work by Kehler, Kertz, Rohde and Elman (2008; Kehler \& Rohde, 2013; Rohde \& Kehler, 2014) instantiates pronoun resolution as a problem of probabilistic inference, for which comprehenders take into account knowledge about the 
probabilities of referents, and about the likelihood of using particular anaphoric expressions to re-mention particular referents, i.e., the "production" biases identified by Arnold (2001).

Such probabilistic accounts of pronoun resolution are consistent with the suggestion that the observed negative relation between referents' prominence and anaphors' explicitness/ informativeness would serve efficient communication. Broadly, anaphors carrying more information would aid the identification (retrieval) of less prominent/ accessible referents (Ariel 1994; Almor, 1999; see Gordon, Grosz, \& Gilliom, 1993; Vonk, Hustinx, \& Simons, 1992, for a similar approach focused on topichood), which are taken to be, under this framework, less frequent or probable referents. Speakers would use anaphoric expressions as cues for their referring intentions, i.e., to refer efficiently (Arnold, 2001; Tily \& Piantadosi, 2009). Comprehenders would, in turn, rely on their knowledge about the relations between anaphoric expressions and referents to guide interpretation, as proposed by Kehler et al. (2008). This knowledge is especially relevant for the interpretation of ambiguous pronouns, that is, for the case when an anaphoric expression is ambiguous between co-referring with one or another potential referent. Put differently, these probabilistic accounts capture the nature of pronoun resolution as a problem of inference under uncertainty: In face of an ambiguous pronominal form, comprehenders are not certain of what was the entity the user intended to mention, and thus can vary in the way they interpret it. In such a variable environment, comprehenders can use their statistical knowledge about pronouns, referents, and their relations, to make better inferences during comprehension.

Such approaches integrate pronoun resolution in the broader domain of learning and adaptation. Rational analysis (Anderson, 1991) attempts to account for cognition as adaptation to an environment that is constantly changing and about which, thus, the system can only make probabilistic assumptions, which can be updated based on experience. In language processing, probabilistic accounts of comprehension (e.g., Crocker \& Brants, 2000; 
Jurafsky, 1996; Levy, 2008) emphasize the role of statistical learning, proposing that people learn and constantly update the frequencies and distributions of the linguistic environment. For example, syntactic parsing reflects comprehenders' expectations, which in turn reflect the statistics of the language to which they have previously been exposed (e.g., Fine \& Jaeger, 2013; Fine, Jaeger, Farmer, \& Qian, 2013; Demberg \& Keller, 2008). More important, language users can track and adapt to changes in a statistical environment: In syntactic comprehension, experiencing structures that are less frequent, or even nonexistent in the language, can render these structures progressively more expected (Fine et al., 2013, Kaschak \& Glenberg, 2004), and in speech perception, listeners increasingly classify a sound that is ambiguous between two phonetic categories (e.g., /b/ and /d/) as indicating a particular category (e.g., /b/), as they have heard the auditorily ambiguous segment paired with information disambiguating it towards that category (Vroomen, van Linden, de Gelder, \& Bertelson, 2007; see also Kleinschmidt \& Jaeger, 2015).

We build on this framework to investigate further probabilistic pronoun resolution. If pronoun resolution is probabilistic, it should be a phenomenon where adaptation can occur, and where different sources of statistical information may be relevant. The work by Kehler et al. (2008) focused on how the probabilities of referents affected the way comprehenders interpreted ambiguous pronouns. Yet, the probabilities of encountering alternative pronominal forms (pronoun probability) should also affect the probabilistic model of the environment that comprehenders build up and update through experience, as detailed in the next section. In fact, under a probabilistic inference approach to reference (e.g., Frank \& Goodman, 2012; Kehler et al., 2008), the statistical distributions of both referents and anaphors (and the distribution of anaphors over referents) can be used to infer a speaker's intended referent, given that the speaker used a particular pronominal form. 
Here, we focus on how pronoun probability (i.e., the frequency of occurrence of alternative pronominal forms) may affect resolution. This is relevant not only for theories that aim at making quantitative predictions about reference resolution (e.g., Frank \& Goodman, 2012; Rohde \& Kehler, 2014) but, crucially, for higher-level explanations of referential communication. Most theories on pronoun resolution have focused on production, proposing that speakers choose different anaphoric expressions to signal different referring intentions (e.g., Ariel, 1990; Arnold, 2001), creating a generative model on which comprehenders can rely to infer those intentions. For example, knowing that the probability of a speaker using a null pronoun to refer to a subject referent is of 0.8 , comprehenders can estimate that a subject antecedent is four times more likely (than an alternative antecedent) the referent of a null pronoun. This would make pronoun interpretation to be accomplished through pure "template matching": Comprehenders would simply apply a learned statistical model of how likely a referent is given a pronominal form. However, there may be differences between speakers, languages or contexts in pronoun use, that would underlie different probabilistic models. The challenge that listeners are facing is that they have to back engineer the circumstances that led a speaker to use an anaphoric expression, which may be an inference process that goes beyond assigning previously learned conditional probabilities of referents given anaphors. Finding that comprehenders can change their interpretation biases depending on the (probabilistic) use of pronouns would be informative about the mechanisms of that inference process and, therefore, about the goals underlying pronoun use and interpretation.

We investigate this hypothesis by testing whether and how changes in the frequency of pronoun use can lead to changes in pronoun resolution and/or in the assumed probability of referents (as detailed in the next section). In particular, we manipulate experimentally the relative probabilities of two alternative ambiguous pronominal forms that comprehenders must interpret. As we shall see in the next section, this may result in changes in pronoun 
interpretation or in changes in the overall likelihood of referencing a particular kind of referent, and thus should be an indicator of what statistical information is relevant in pronoun resolution. Following work suggesting that comprehenders adapt their expectations to match, or approximate, environment-specific statistics, we expect to find such changes to be a function of the relative likelihood of these forms in an experimental environment. This way, we investigate whether and what statistical information is relevant when comprehenders determine the generative model underlying the speaker's production. This will provide insights to theories of reference and the relation between anaphor use and interpretation. We also extend previous work on adaptation in language processing to a case where comprehenders do not simply apply statistical knowledge that was explicitly given in a novel environment, but instead infer, from the statistics of the novel statistical environment, the underlying rules of pronoun use and interpretation. (We will return to this issue in the General Discussion).

How might pronoun probability affect ambiguous pronoun resolution?

The probabilistic model underlying pronoun use and interpretation, thus, makes reference to statistical distributions of referents and pronominal forms. This means that only an experimental environment containing alternative referents and alternative forms can provide a direct test of how pronoun probability impacts pronoun resolution. When analysing the interpretation bias of a single pronominal form he towards subject or object referents, as in Rohde and Kehler's (2014) first experiment (in the pronoun prompt condition), the probability of the two potential referents was manipulated through verb semantics, but the probability of the anaphoric form (he) was constant (i.e., it was always $p=1$ ). This experimental environment with only one pronominal form does not replicate the commonly 
tested (and theoretically relevant) context where each of two pronominal forms can co-occur with each of two potential referents. Consider the case where comprehenders have to interpret null or overt ambiguous pronouns that can co-refer with either a subject or an object referent, in sentences such as The athlete consulted the orthopaedist at the hospital when he/ Ø returned from Italy. Every outcome has two attributes, "Form" and "Referent", that assume particular values as comprehenders interpret each sentence: For example, in a sentence where he is interpreted as co-referring with the object referent, orthopaedist, the outcome is the cooccurrence of "overt" and "object". The probabilities of each possible combination of values of Form and Referent are the conjoint probabilities $\mathrm{p}\left(\mathrm{A}^{\wedge} \mathrm{B}\right)$, as illustrated in Table 1 for a hypothetical result of the above example case (where "Subj" and "Obj" indicate the selection of a subject or an object as the pronoun referent). For each value of each attribute (e.g., the value "Obj" for Referent), the sum across the corresponding conjoint probabilities $\left(\mathrm{p}\left(\mathrm{Obj}^{\wedge} \mathrm{Null}\right)+\mathrm{p}\left(\mathrm{Obj}^{\wedge} \mathrm{Overt}\right)\right)$ is the marginal probability, $\mathrm{p}(\mathrm{Obj})$, and indicates the probability that comprehenders select an object referent, on average, across the pronominal forms (here, 0.5). Likewise, the marginal probabilities of each Form, $\mathrm{p}(\mathrm{Null})$ and $\mathrm{p}(\mathrm{Overt})$, indicate the probabilities of occurrence of each pronominal form, across referents.

\section{[TABLE 1 NEAR HERE]}

We are interested in resolution preferences, that is, in the conditional probabilities of referents given pronominal forms. These conditional probabilities, which restrict consideration to a particular Form, are the ratios between the conjoint probabilities and the marginal probabilities of the pronominal forms: $\mathrm{p}(\mathrm{A} \mid \mathrm{B})=\mathrm{p}\left(\mathrm{A}^{\wedge} \mathrm{B}\right) / \mathrm{p}(\mathrm{B})(\mathrm{e} . \mathrm{g} .$, Kolmogorov, 1956), and are presented within parentheses in Table 1. For example, the probability of a 
subject referent given a null pronoun, $\mathrm{p}(\mathrm{Subj} \mid \mathrm{Null})$, corresponds to the ratio between the conjoint probability of occurrence of a Subject referent and a Null pronoun, and the marginal probability of Null pronouns, $\mathrm{p}\left(\mathrm{Subj}^{\wedge} \mathrm{Null}\right) / \mathrm{p}(\mathrm{Null})$. Crucially, these values depend on the marginal probabilities of overt and null pronouns, suggesting that the interpretation of alternative anaphoric forms might be affected by the relative probabilities of those forms.

[FIGURE 1 NEAR HERE]

Figure 1 illustrates how varying the marginal probabilities of pronominal forms (in the current example, by increasing the marginal probability of null pronouns), while keeping resolution biases constant (here, $\mathrm{p}(\mathrm{Subj} \mid \mathrm{Null})=0.8$ and $\mathrm{p}(\mathrm{Obj} \mid \mathrm{Overt})=0.8)$, leads to changes in the marginal probabilities of referents (here, an increase in the marginal probability of Subj, and the concurrent decrease in the marginal probability of $\mathrm{Obj}$ ). That is, if comprehenders would interpret pronouns, in an environment with a higher probability of null (and a lower probability of overt) pronouns, in the same way as in an environment with uniformly distributed pronominal forms, there would be a higher marginal probability of Subj, and a lower marginal probability of $\mathrm{Obj}$, in the former, relative to latter statistical environment ( 0.65 and 0.35 , relative to 0.5 . and 0.5 , for the cases of $0.75 / 0.25$ and $0.5 / 0.5$ distributions of null/overt pronouns, indicated by the vertical dotdash and dotted lines, respectively). Under this first hypothesis, comprehenders would use the probabilistic knowledge about the likelihood of referents given anaphoric forms (e.g., $\mathrm{p}(\mathrm{Subj} \mid \mathrm{Null}))$ that they had obtained through experience within the language, and would apply it regardless of variations in the likelihood of anaphoric forms (e.g., p(Null)). As a consequence, they would infer that, by using more Null pronouns (i.e., in an unequally distributed environment), the speaker 
signalled the intention of mentioning more subject referents, and fewer object referents (i.e., higher $\mathrm{p}(\mathrm{Subj})$ and lower $\mathrm{p}(\mathrm{Obj}))$. In other words, pronoun interpretation would replicate previous interpretation experiences, even if that would lead a comprehender to infer that a speaker might be referring to a type of referent (say, subject) with a higher likelihood than expected given the frequency of references to subjects in the language.

However, experience within the language also gives comprehenders probabilistic knowledge about the likelihood of speakers to refer to subject and object referents. There is prior evidence that comprehenders can keep track of how frequently a speaker refers to a referent, based on recent experience (Metzing \& Brennan, 2003). Likewise, comprehenders have expectations, based on prior experience (i.e., in the language), for the frequencies with which subject and object referents are referred to, and they might use this knowledge to guide interpretation. That is, they might rely more on their knowledge about the marginal probabilities of referents $(\mathrm{p}(\mathrm{Subj})$ and $\mathrm{p}(\mathrm{Obj}))$, and change their interpretation biases (e.g., $\mathrm{p}($ Subj|Null)) so as to keep those probabilities constant in face of variations in the probabilities of pronominal forms (e.g., p(Null)). According to this second hypothesis, comprehension would be guided by the (prior) probabilistic knowledge about how frequently subject and object entities are re-mentioned, which would be used to infer about the conditional probabilities of referents given forms (e.g., p(Subj|Null)). For example, comprehenders might rely on the knowledge that speakers are equally likely to refer to subject and object entities (as hypothesised in Table 1) and use that information to infer that, in an environment with a higher probability of null (and a lower probability of overt) pronouns, the conditional probabilities of referents given forms (e.g., $\mathrm{p}(\mathrm{Subj} \mid \mathrm{Null}))$ differ from the ones that were learned from previous experience in the language. In order to avoid a substantial increase in the inferred subject references and a decrease in the inferred object references in an environment with increased probability of null pronouns, comprehenders 
should change their resolution preferences either by increasing the resolution preference of overt pronouns towards object referents, decreasing the resolution preference of null pronouns towards subject referents, or a combination of both, as illustrated in Figure 2.

\section{[FIGURE 2 NEAR HERE]}

Such a result would strongly suggest that the way comprehenders resolve pronouns is affected by the relative probabilities of pronominal forms in the environment. It would also indicate that comprehenders can track the frequency with which pronominal forms are used in a new environment, in line with prior evidence of changes in expectations for the frequencies with which lexical items such as quantifiers will be used, given recent experience (Yildirim, Degen, Tanenhaus, \& Jaeger, 2016). Finally, it would suggest that adaptation to those changes would be driven primarily by the statistical knowledge about the (marginal) probabilities of referents. In other words, it would indicate that the goal of adaptation (Anderson, 1991) in pronoun resolution may be to maintain constant the relative probabilities of referents across variations in pronoun probability.

We conducted two experiments assessing interpretation biases of null and overt pronouns towards subject and object referents, in two varieties of Portuguese, taking advantage of the fact that these varieties are known to differ in the frequency of use of overt and null pronouns, as well as in the interpretation biases of these pronominal forms. By manipulating experimentally the marginal probabilities of overt and null pronouns, we test directly whether pronoun probability affects pronoun interpretation, and how comprehenders adapt to variations in the distribution of pronouns in the environment. The fact that the two 
varieties vary in the base rate of pronoun use (and in interpretation) allows us, additionally, to test whether and how comprehenders integrate previous experience with evidence from a new statistical environment: In particular, an experimental environment with fewer overt pronouns should imply a greater change to the estimated probability of those pronouns by comprehenders of the variety where there is a predominant use of overt forms, relative to comprehenders of the variety where there is a scarcer use of overt forms (as detailed in next section).

\section{The current study}

We tested Portuguese sentences such as (1), with a main clause introducing two referents ${ }^{\mathrm{iii}}$ and a subordinate clause where the grammatical subject is either an overt (he) or a null $(\varnothing)$ pronoun ambiguously co-referring with the subject (athlete) or object (orthopaedist) of the main clause.

(1) O atleta ${ }_{\left[\mathrm{Subj}_{j}\right]}$ consultou o ortopedista ${ }_{[\mathrm{Obj}]}$ no hospital quando ele/ $\varnothing$ regressou da viagem a Itália.

The athlete ${ }_{[\mathrm{Subj}]}$ consulted the orthopaedist ${ }_{[\mathrm{Obj}]}$ at the hospital when he/ Ø returned from the journey to Italy.

The first and main question we want to address is whether the relative probability of pronominal forms affects their resolution. We manipulated pronoun probability within the experiment by varying how many null and overt pronouns were presented: Half of the 
participants were faced with an environment with $50 \%$ null and $50 \%$ overt pronouns (equal distribution), whereas the other half was presented with a statistical environment with $75 \%$ null and $25 \%$ overt pronouns (unequal distribution). We thus varied the (relative) frequencies of pronominal forms, which can be tracked as probabilities: Across the experimental session, the marginal probabilities $\mathrm{p}(\mathrm{Overt})$ vs. $\mathrm{p}(\mathrm{Null})$ will be 0.5 vs. 0.5 , in the equal distribution condition, and 0.25 vs. 0.75 , in the unequal distribution condition. We build on prior evidence (e.g., Yildirim et al., 2016) to hypothesize that comprehenders will track the differences in the relative probabilities of overt and null pronouns in our experimental contexts. Given these differences, we expect to observe changes either in how likely subject and object entities are taken to be referents, or in how likely each pronoun is resolved towards those referents (or both). Note that, in our experiments, participants can only learn, from the experimental environment, the statistics concerning the relative frequency of pronominal forms. That is, they cannot learn about referents' probabilities, neither about conditional probabilities of referents given pronouns, and thus knowledge about these is assumed to be the one obtained through experience within the language (i.e., from prior experience).

We have considered above (Table 1) a hypothetical case where comprehenders display strong resolution preferences for subject referents given null pronouns, and for object referents given overt pronouns (i.e., $\mathrm{p}(\mathrm{Subj} \mid \mathrm{Null})$ and $\mathrm{p}(\mathrm{Obj} \mid \mathrm{Overt}))$. Research has shown that this is not always the case, however. We conducted our experiments in Brazilian and European Portuguese (BP, EP), taking advantage of the fact that the two varieties differ both in interpretation biases observed in studies with a uniform distribution of overt and null pronouns (see, e.g., Filiaci et al., 2013, for similar differences in Italian vs. Spanish), and in the relative probabilities of these pronominal forms in the language. On the one hand, EP shows strong subject and object biases in interpretation of null and overt pronouns, respectively (approximately 80\%), whereas in BP the subject-bias for null pronouns is strong 
but the object-bias for overt pronouns is around 60\% (Corrêa, 1998; Costa, Faria, \& Matos, 1998; Luegi, Costa, \& Maia, 2014; Teixeira, Fonseca, \& Soares, 2014). On the other hand, in EP the frequency of null pronouns is higher than the frequency of overt pronouns, whereas $\mathrm{BP}$ is claimed to be in a change process leading to a progressive lower frequency of use of null pronouns, and corresponding higher frequency of overt pronouns (Barbosa, Duarte, \& Kato, 2005; Duarte, 1993, 2000) $)^{\text {iv }}$.

Our equal distribution condition is intended to replicate previous findings for the interpretation biases in $\mathrm{BP}$ and $\mathrm{EP}$, assessed in experiments where there was an equal number of null and overt pronouns. We thus expect to observe, in this condition, an object-bias in the interpretation of overt pronouns that shall be weaker in BP and stronger in EP. The weaker interpretation bias in BP should be more prone (than a strong bias) to observable changes given a new statistical environment, as it reflects comprehenders' higher uncertainty about the referring intentions of a speaker when he uses an overt pronoun, that is, a weaker belief about what referent is signalled by the use of the overt pronoun. Thus, we may expect any observed differences between distribution conditions, in how pronouns are resolved, to be stronger in BP (relative to EP), and in the overt pronoun condition (compared to the null pronoun condition).

Moreover, a distribution biased towards null pronouns should more strongly diverge from the statistics in the language observed in BP. This is why we chose to bias the unequal distribution in this direction. When language users adapt to a novel statistical environment (e.g., Anderson, 1991), they integrate new evidence with their prior statistical knowledge in order to adjust their beliefs about relevant linguistic statistical properties. Accordingly, adaptation to the statistics of the experiment should be affected by prior (i.e., before the experiment) knowledge of how likely null and overt pronouns are. Given that, for BP, the statistics in the unequal distribution condition diverge strongly from the statistics in the 
language, we might expect that this is where greater changes should be imposed to the statistical model of the environment that comprehenders are updating, as assumed e.g., in error-based learning algorithms (e.g., Chang, Dell, \& Bock, 2006; Rumelhart, Hinton, \& Williams, 1986), or in other models of supervised learning such as Bayesian belief update (e.g., Courville, Daw, \& Touretzky, 2006).

\section{Experiment 1: Offline questionnaires}

Experiment 1 employed sentence interpretation questionnaires to investigate the resolution of overt and null pronouns in $\mathrm{BP}$ and $\mathrm{EP}$, and its modulation by the probability of the pronominal forms.

\section{Methods}

\section{Participants}

Twenty-four monolingual speakers of European Portuguese (aged 23.5 \pm 7.1) from the University of Lisbon and twenty-one monolingual speakers of Brazilian Portuguese (aged 21 \pm 3.6 ) from the Federal University of Rio Grande do Sul gave their informed consent and participated voluntarily in the experiment.

\section{Design and Materials}

We created 32 sentences such as (2) (see Appendix A for a full list of experimental items). We used the same sentences for EP and BP, except for a few small adjustments at the lexical level (e.g., hospedeira (EP) and aeromoça (BP), meaning flight attendant). 
(2) $\mathrm{O}$ atleta ${ }_{[\mathrm{Subj}]}$ consultou o ortopedista ${ }_{[\mathrm{Obj}]}$ no hospital quando ele/ $\varnothing$ regressou da viagem a Itália.

The athlete ${ }_{[\mathrm{Subj}]}$ consulted the orthopaedist ${ }_{[\mathrm{Obj}]}$ at the hospital when he/ Ø returned from the journey to Italy.

Each sentence had a main clause and a subordinate temporal clause introduced by quando (when). The main clause introduced two human referents (common nouns), and the subordinate clause was headed by either an overt $(h e)$ or a null $(\varnothing)$ subject pronoun ambiguously co-referring with the first (the athlete) or the second (the orthopaedist) referent, i.e., the subject or object of the main clause, respectively. Fifteen of the items had feminine and 17 had masculine referents (and pronouns, in the overt pronoun condition).

Participants were exposed either to an equal number of overt and null pronouns or to an unequal number of the two forms, with $75 \%$ null pronouns. Our design thus crossed Variety (between-participants, BP vs. EP), Distribution (between-participants, EqualDistribution vs. Unequal-Distribution) and Pronoun (within-participants, Null vs. Overt). For each variety, we created four lists crossing Pronoun and Distribution according to a Latin Square design ${ }^{\mathrm{v}}$. In addition to the experimental items, we constructed 64 filler sentences that did not contain overt or null pronouns. Of these, 32 sentences (constructed for another study) were ambiguous as to the agent of the described action, making the experimental manipulation not readily perceivable by participants. The remaining 32 fillers were unambiguous, allowing us to have a measure of participants' attention, as reflected by the accuracy in answering the comprehension questions that followed each sentence. 
Acceptability Pre-tests

In order to test the overall acceptability of our experimental sentences, and to identify potential differences in acceptability between sentences containing overt and sentences containing null pronouns, we pretested our materials. Participants ( $\mathrm{N}=19$ and $\mathrm{N}=26$ for $\mathrm{BP}$ and EP respectively, recruited from the Universities of Lisbon and Rio Grande do Sul; these were different participants from the ones completing the questionnaire that constitutes Experiment 1) were asked to score the acceptability of each sentence on a Likert scale form 1 (not acceptable at all) to 7 (completely acceptable). All sentences were rated as highly acceptable (BP: mean 5.3, $\mathrm{SD}=1.5$; $\mathrm{EP}:$ mean $4.8, \mathrm{SD}=1.4$ ), and no item had a mean acceptability below 3.5. Acceptability was not significantly different for overt (BP: mean 6.34, $\mathrm{SD}=0.80$; $\mathrm{EP}:$ mean 4.37, $\mathrm{SD}=0.69)$ and null $(\mathrm{BP}:$ mean $6.40, \mathrm{SD}=0.65 ; \mathrm{EP}$ : mean 4.23, $\mathrm{SD}=0.65)$ pronoun sentences, as indicated by Wilcoxon Signed-Ranks Tests $(\mathrm{V}=356, \mathrm{p}=$ $.25 ; \mathrm{V}=365.5, \mathrm{p}=.5)$. The pretest was conducted online using OnExp (https://onexp.textstrukturen.uni-goettingen.de/).

\section{Procedure}

Participants were randomly assigned to the lists, each containing a total of 96 sentences, presented in an individually randomized order, with the constraint that at least one filler item occurred between two experimental sentences.

Participants were instructed to read each sentence and answer the corresponding question. Sentences appeared on the screen, one at a time, followed by a question about the agent performing the action described by the temporal subordinate clause (for sentence (2), 
Who returned form the journey to Italy?) and two possible answers (e.g., The athlete, The orthopaedist, with their order of presentation on the screen counterbalanced). After clicking on the button corresponding to the selected answer, the next sentence was presented. Sentences were presented and responses recorded using the Internet-based platform IbexFarm (Drummond, 2013; http://spellout.net/ibexfarm). A practice block of five sentences preceded the actual task list.

\section{Analysis}

Here and in the analysis reported for Experiment 2, we implemented linear mixed models in the lme4 package (Bates, Maechler, Bolker, \& Walker, 2015) in $R$ (R Development Core Team, 2008).

We removed from the analysis the data from one (BP speaker) participant that answered correctly to only $40 \%$ of the unambiguous comprehension questions following the fillers. We analysed the data from the remaining 44 participants, who were accurate in more than $60 \%$ of the answers $(\mathrm{BP}:$ mean $=94.7, \mathrm{SD}=10.5 ; \mathrm{EP}:$ mean $=97.9, \mathrm{SD}=5.7)$.

We fitted a mixed logit regression (Jaeger, 2008) to our binomial outcomes (coded 1: object, and 0: subject) to analyse the choices of object vs. subject as the pronoun referent, using glmer with a "logit" link function. Because our hypothesis of adaptation is based on the assumption that participants can track the statistics of an experimental context, and given that the presentation of items was randomized, we added a predictor, POvert, coding for the (relative) probability of overt pronouns in previous trials, at each point in the experiment. For each participant and at each experimental trial $t$, POvert was computed as the ratio between the number of experimental trials containing overt pronouns and the total number of experimental trials, from trial 1 to trial $t-1$ (we excluded the first trial from the analysis, for 
which it is not possible to compute POvert, removing 44 of 1408 observations, i.e., $\cong 3 \%$ of the data). This predictor gives us a finer-grained measure of within-participants variability in the relative probability of overt and null pronouns ${ }^{\mathrm{vi}}$.

Our model included all main effects and interactions with a maximal-random structure justified by the design (Barr, Levy, Scheepers, \& Tily, 2013; in particular, we excluded by-subject random slopes for the between-participants' predictors Distribution and Variety). All predictors were centered in order to reduce collinearity. The full model we report includes Pronoun (Null, -0.4 vs. Overt, 0.6), Distribution (Equal, -0.5 vs. Unequal, $0.5)$, Variety (BP, -0.55 ; EP, 0.45 ), and POvert (continuous, from -0.38 to 0.62 ), as fixed effects. The random effects were Participant (44) and Item (32), entered as intercept, as well as uncorrelated slopes of the fixed predictors (when justified, see above).

\section{Results}

Figure 3 plots the mean percentages of object responses (out of object and subject responses) for the conditions crossing Pronoun, Distribution, and Variety, and Table 2 summarizes the fitted model, where positive coefficients indicate increased log-odds (i.e., increased probabilities) of selecting "object".

[FIGURE 3 NEAR HERE]

[TABLE 2 NEAR HERE] 
Replicating previous work, we observe that, in an environment where null and overt pronouns were equally distributed, both Brazilian and Portuguese participants chose more subjects as referents of null pronouns, but differed in the interpretation of overt pronouns, for which BP participants chose object referents roughly at chance level (46\%), whereas EP comprehenders chose object referents in $76 \%$ of cases (marginally significant interaction between Pronoun and Variety). Crucially, this pattern changed in the unequal distribution condition: The interaction between Pronoun and Distribution indicates that object choices for overt pronouns increased in the unequal distribution condition (to $69 \%$ and $83 \%$ for BP and EP, respectively), relative to the equal distribution condition. That is, $\mathrm{p}(\mathrm{Object|Overt)}$ increased in an environment biased towards a lower frequency of overt pronouns. This was especially the case for BP, as indicated by the three-way interaction between Pronoun, Variety, and Distribution.

Moreover, the likelihood of choosing an object referent was modulated by POvert: There was a trend for increasing assignment of object referents as POvert decreased. The interaction Pronoun:Variety:POvert indicates that, in EP, this is especially the case for overt pronouns, whereas in BP it is observed also for null pronouns. Figure 4, showing the probabilities of an object answer for overt and null pronouns, averaged for each value of POvert (computed across distribution conditions, participants and items), illustrates this pattern.

[FIGURE 4 NEAR HERE]

\section{Discussion}

Experiment 1 showed that participants differed in how likely they interpreted null and overt pronouns as co-referring with subject or object referents, depending on the relative 
probabilities of the two pronominal forms in the environment: The likelihood of selecting object referents for overt pronouns was higher in an environment where these forms were less frequent. This result indicates that pronoun resolution was affected by pronoun probability, and that comprehenders adapted to the statistical environment of the experiment.

The effect of Distribution was stronger for BP (three-way interaction Pronoun:Variety:Distribution, $\mathrm{p}<.05)$, the variety for which there is, in the language, a higher frequency of overt (relative to null) pronouns. This further suggests that comprehenders integrated their prior statistical knowledge with the new statistical pattern in the experimental context. In the unequal distribution condition, BP participants are faced with a statistical environment that strongly deviates from the one of their everyday life and, thus, where the update of the probabilistic model of the environment should be greater, and any consequences of it should be more likely observable. In fact, the higher the deviation between the expected statistics given prior experience and the observed statistics in a current environment, the more comprehenders need to adapt, as assumed by models of learning and adaptation (e.g., Chang et al., 2006; Courville et al., 2006). In support of this hypothesis, we found, importantly, that Brazilian participants made increasing choices of object referents as they had encountered fewer overt pronouns in previous trials, that is, the more they had been facing a statistical environment strongly diverging from the one of their language, as measured by incremental decrease in POvert.

Moreover, given the finer-grained variations in the relative probabilities of null and overt pronouns, captured by our predictor POvert, we observe, for BP, an increasing assignment of object referents to null pronouns with decreasing probability of overt pronouns, alongside the increasing assignment of those referents to overt pronouns (Figure 4). That is, there is also a trend for Brazilian participants to increasingly choose object referents for null pronouns as overt pronouns become progressively less frequent ${ }^{\mathrm{vii}}$. Overall, 
as the proportion of overt pronouns decreased, comprehenders adjusted their resolution preferences in a way that favoured object referents, i.e., the referents more likely taken to be signalled by overt pronouns. In EP, this was reflected in an increased object-biased interpretation of overt pronouns, and in BP in both an increased object-biased interpretation of overt pronouns and a decreased subject-biased interpretation of null pronouns.

We hypothesized in the Introduction that, in face of a novel environment with a higher frequency of null (and lower frequency of overt) pronouns, we might expect to observe either increasing references to subject antecedents or changes in resolution preferences, such as increased $\mathrm{p}(\mathrm{Obj} \mid \mathrm{Overt})$. Experiment 1 provides support to the second hypothesis, suggesting that changing the strength of the interpretation biases might serve to avoid variations in the marginal probabilities of subject and object referents due to variations in the relative probabilities of overt and null pronouns. Under this hypothesis, comprehenders would infer that the speaker intended to make references to objects and subjects and thus that, when using a reduced number of overt pronouns, these had to signal more strongly the intention of referring to an object antecedent. This would be especially relevant for BP speakers, whose weak object-bias in interpreting pronouns would lead to the inference that, in the unequal distribution context, the speaker had almost exclusively intended to refer to subjects. According to this interpretation, we might expect comprehenders to choose object (and subject) answers equally likely in the equal and unequal distribution conditions. We performed additional Welch Two Sample t-tests to compare the mean answer (i.e., across object, coded 1 , and subject, coded 0 ) in the two distribution conditions. This difference was not significant for BP (means $=0.36,0.30 ; 95 \%$ CIs $[-0.01,0.13])$, though it reached significance for EP (means $=0.48,0.36 ; 95 \%$ CIs $[0.05,0.19])$. Thus, although the data from Experiment 1 are evidence of an adaptive behaviour in pronoun resolution, they are not 
conclusive about the hypothesized goal of that behaviour. (We will return to this issue in the General Discussion.)

Experiment 1 provided preliminary evidence for adaptation in pronoun resolution, whereby participants interpreted with increasing likelihood overt pronouns as co-referring with object referents as these pronouns became less frequent in the experimental context. An important question that remains open is, however, whether such effects can be detected during online processing, i.e., in a task with higher ecological validity and where potential strategic or metalinguistic effects of final interpretation choices may be minimized (Sanford, Sturt, Moxey, Morrow, \& Emmott, 2004). Experiment 2 was conducted to address this question.

\section{Experiment 2: Visual-World Study}

Experiment 2 employed a Visual-World Paradigm (VWP), where spoken sentence comprehension is performed concurrently with exposure to a visual context, allowing the assessment of online incremental language processing (see Huettig, Rommers, \& Meyer, 2011, for a review). It is well known that listeners make anticipatory looks to depicted objects that relate to upcoming linguistic material (e.g., Kamide, Altmann, \& Haywood, 2003). More important, eye fixations are time-locked to the identification of referents for ambiguous phrases (e.g., Tanenhaus, Spivey-Knowlton, Eberhard, \& Sedivy, 1995) and pronouns (e.g., Arnold, Eisenband, Brown-Schmidt, \& Trueswell, 2000; see also Colonna, Schimke, \& Hemforth; Järvikivi et al., 2005, Kaiser \& Trueswell, 2008), making the VWP a well-suited method to investigate online referential processing (Boland, 2004; Kaiser, 2016). We build on this prior research to interpret, in Experiment 2, fixations to depicted potential referents of pronouns as an index of online pronoun resolution. 


\section{Methods}

Participants

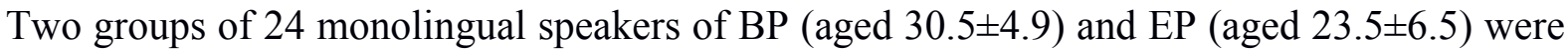
recruited among Brazilian and Portuguese students of different universities in Paris. They gave their informed consent and were paid eight euros for their participation. All subjects had normal or corrected-to-normal vision.

\section{Design and Materials}

We used the same materials as in Experiment 1, where the (32) experimental sentences consisted of a main clause that introduced two potential referents in the subject and object positions, and a subordinate temporal clause containing an ambiguous null or overt subject, as in (2), repeated below as (3).

(3) $\mathrm{O}$ atleta ${ }_{[\mathrm{Subj}]}$ consultou o ortopedista ${ }_{[\mathrm{Obj}]}$ no hospital quando ele/ $\varnothing$ regressou da viagem a Itália.

The athlete ${ }_{[\mathrm{Subj}]}$ consulted the orthopaedist ${ }_{[\mathrm{Obj}]}$ at the hospital when he/ Ø returned from the journey to Italy.

For each group (BP and EP), half of the participants were assigned to lists where the null and overt pronouns occurred equally often (equal distribution) and the other half were 
presented with lists with $75 \%$ of null pronouns and $25 \%$ of overt pronouns (unequal distribution). The design thus crossed Variety (between-participants, BP vs. EP), Distribution (between-participants, Equal vs. Unequal) and Pronoun (within-participants, Null vs. Overt), as in Experiment 1.

Sentences were recorded on a Zoom H2 portable microphone, inside an anechoic chamber, by female native speakers of European and Brazilian Portuguese instructed to use a neutral intonation. The mono recordings were registered at $44.1 \mathrm{~Hz}$, saved as 16 bit wavefiles and edited: For each item, the offset of quando ("when") and the onsets of the verb (e.g., returned) and of the post verbal phrase (e.g., from the journey to Italy) were hand-coded in milliseconds (EP means: $5683 \mathrm{~ms}(\mathrm{SD}=568 \mathrm{~ms}), 6059 \mathrm{~ms}(\mathrm{SD}=608)$ and $6862 \mathrm{~ms}(\mathrm{SD}=$ 693); BP means: $5741 \mathrm{~ms}(\mathrm{SD}=389 \mathrm{~ms}), 6056 \mathrm{~ms}(\mathrm{SD}=425)$ and $6869 \mathrm{~ms}(\mathrm{SD}=487)$, respectively). The differences between BP and EP were not significant (all ps $>.5$ ) according to within-items t-tests.

Each spoken sentence was paired with a visual context comprising four objects corresponding to the two human entities that are the possible pronoun referents (ATHLETE and ORTHOPAEDIST in (3), i.e., the subject and object referents), a location (HOSPITAL) and a distractor object (see Figure 5). The visual objects were pasted into images at 1024x768 pixels resolution and saved as PNG files. The location picture was intended to avoid spillover fixations from the object (e.g., ORTHOPAEDIST) to contaminate fixations at the pronoun region, as the location was mentioned between the two regions. That is, mentioning "the hospital" would trigger fixations to its visual referent, and further fixations at THE ORTHOPAEDIST could thus be interpreted as triggered by further linguistic information. The inclusion of a distractor object was intended to promote the continuous allocation of visual attention along the sentence unfolding and thus to prevent participants from developing looking strategies (e.g., always looking at the two possible pronoun referents). Half of the 
filler sentences had comprehension questions concerning the distractor, thereby encouraging participants to also pay attention to this object. Moreover, accuracy on these questions (for which there were a correct and an incorrect answer) allowed us to assess the overall attention in the task. Each experimental sentence was followed by a question about the agent performing the action described by the subordinate clause headed by the pronoun, as in Experiment 1.

\section{[FIGURE 5 NEAR HERE]}

Finally, all objects had roughly the same size and were arranged in the array so that their position was counterbalanced (across items, the entities depicting the subject, object, location and distractor appeared equally often in the four positions) and the distance between every two depicted objects was no smaller than 250 pixels. This corresponds to about 5 degrees of visual angle, i.e., more than twice the 2 visual angle degrees at which object recognition deteriorates (e.g., Nelson \& Loftus, 1980), guaranteeing that fixations on one object revealed processing only of that specific object, and that a saccade should be made for another object to be fixated.

\section{Procedure}

Participants' eye movements were recorded using an EyeLink® II head-mounted eye-tracker at a sampling rate of $500 \mathrm{~Hz}$ on a 21 "screen (1024 x 768 px. image resolution). Viewing was binocular but only the participant's dominant eye was tracked (pupil-only tracking). Presentation of the spoken sentences was made through a satellite speaker connected to the participant's PC. 
The initial screen instructed participants to listen carefully to auditory sentences while paying attention to the visual context in preparation for comprehension questions. Then, after a nine-point calibration (accepting only deviations smaller than 1), the presentation of the stimuli began, with five initial practice trials preceding the List materials.

Each trial started with a fixation prompt in the centre of the screen that the participant had to fixate, which allowed a drift correction and triggered the presentation of the visualworld stimulus. Each stimulus presented concurrently the visual context (previewed for one second) and the corresponding spoken sentence. The visual context remained on the screen for one second after the spoken sentence terminated, followed by a screen where the (written) comprehension question was presented alongside two possible answers, at the left and right of the screen (counterbalanced). After choosing one answer (with the A and L keys on the keyboard, corresponding to the answers on the left and right part of the screen), a new trial started. The experiment lasted for approximately 40 minutes, and had a pause after presentation of half of the items.

\section{Analysis}

All 48 participants answered correctly more than $60 \%$ of the comprehension questions that followed 32 unambiguous fillers $(\mathrm{BP}:$ mean $=84.4, \mathrm{SD}=6.9$; $\mathrm{EP}:$ mean $=86.6, \mathrm{SD}=4.9)$, and thus all participants' data were analysed.

We used (SR Research Experiment Builder's) Screen Builder to draw four interest areas (IAs) approximately 40 pixels around the depicted entities and labelling them as: The pronoun referents (subject and object), the location, and the distractor visual objects. Fixation data was then mapped onto these areas. A fixation on the IA was counted from the onset of the saccade leading into it. We considered fixation data from the offset of quando ("when") 
till $1500 \mathrm{~ms}$ after it (with $200 \mathrm{~ms}$ added to account for eye movement programming/ execution). This window comprised the pronoun (phonetically realized or not ${ }^{\text {viii }}$, the verb, and the very beginning of the following phrase (specifically, it extends $350 \mathrm{~ms}$ beyond the mean onset $(1153 \mathrm{~ms}, \mathrm{SD}=296)$ of the post-verbal phrase, which had an average duration of $2600 \mathrm{~ms}$; note that the post-verbal material did not disambiguate the pronoun).

In line with previous research, we expected to observe increasing fixations to visual referents starting around $400 \mathrm{~ms}$ after the pronoun and extending to the following linguistic regions (Arnold et al., 2000). For example, when participants heard he returned in the spoken sentence The athlete consulted the orthopaedist at the hospital when he returned form the journey to Italy, looks to 'THE ORTHOPAEDIST' would reveal an interpretation of the overt pronoun as co-referring with the object of the main clause.

We focused on fixations to the depicted object and subject referents (OBJ and SUBJ from now on, ORTHOPAEDIST and ATHLETE in our example). On an item-by-item basis, we first unfolded the fixation data over a time-course in windows of $1 \mathrm{~ms}$ each and considered the data from the offset of when. We then calculated, as our dependent measures, i) the proportion of fixations to $\mathrm{OBJ}$, and ii) the proportion of fixations to SUBJ, relative to all four IAs, in windows of $50 \mathrm{~ms}$ (to reduce correlation between consecutive time-points, see, e.g., Coco, Keller, \& Malcom, 2015, and references therein). Since visual attention in our visual-world trials is allocated not only to these visual objects, but also to the location and distractor objects, the proportion of fixations to SUBJ and the proportion of fixations to OBJ do not sum up to one when other objects were also fixated. That is, SUBJ and OBJ do not exhaust the space of possible objects to be fixated. We thus analysed each separately. For the sake of brevity, we present in the text the analysis on fixations to OBJ, where we expected, following the results of Experiment 1, to find effects of referential form distribution. Results of the analysis of fixations to SUBJ can be found in Appendix B. 
We first analysed the time-course of such dependent measures along 30 bins of $50 \mathrm{~ms}$ (i.e., during the $1500 \mathrm{~ms}$ time-window of interest), by performing growth curve analysis (Mirman, Dixon, \& Magnuson, 2008) where a linear term (Time) has the same interpretation as a linear regression of fixations over time ${ }^{\mathrm{ix}}$. The experimental predictors were the same as in Experiment 1: Pronoun (Null, -0.4 vs. Overt, 0.6), Distribution (Equal, -0.5 vs. Unequal, $0.5)$, and Variety (BP, -0.5 ; EP, 0.5). These fixed effects and the random effects Participant (48) and Item (32) were entered in a maximal (see Experiment 1 for details on the justified model in our design) linear-mixed effect model (using lmer function in R).

Then, we analysed how fixations to OBJ and fixations to SUBJ would be predicted by the same measure $\mathrm{P}(\mathrm{Overt})$ we used in Experiment 1. In this case, we did not include the predictor directly in the time-course analysis as, on one hand, the explanatory power of it would be inflated by the data-point repetition along each single trial (i.e., along the 30 bins analysed at each trial) and, on the other hand, we are interested in assessing the overall (across bins) amount of visual attention allocated to OBJ and SUBJ at each trial associated with a particular $\mathrm{P}(\mathrm{Overt})$. Thus, we first calculated the average (across bins) proportion of fixations to OBJ and proportion of fixations to SUBJ for each trial and participant, and then ran a maximal model on this dependent measure, where the fixed predictors (centered) were Pronoun (Null, -0.4 vs. Overt, 0.6), Distribution (Equal, -0.5 vs. Unequal, 0.5), Variety (BP, -0.5 ; EP, 0.5), and $\mathrm{P}($ Overt) (continuous, ranging from -0.37 to 0.63$)$, and the random effects were Participant (48) and Item (32). We report the coefficient estimates of the model predictors, their standard error, the t-value, and derived p-values (by treating the t-statistic using the standard normal distribution as a reference; e.g., Barr et al., 2013) ${ }^{\mathrm{x}}$.

\section{Results}

Time-course of Fixations 
Figure 6 plots the time-course of proportion of fixations to OBJ along $1500 \mathrm{~ms}$ from the offset of when, and Table 3 presents the summary of the fitted model.

[FIGURE 6 NEAR HERE]

[TABLE 3 NEAR HERE]

There were more and increasing fixations to OBJ in the overt (relative to the null) pronoun condition, across Variety and Distribution conditions, as indicated by the main effect of Pronoun, and the interaction Pronoun:Time (assuming a positive value for overt pronouns). Crucially, the increase in proportion of fixations to OBJ in the overt pronoun condition is higher in $\mathrm{BP}$, relative to $\mathrm{EP}$, and, in $\mathrm{BP}$, in the unequal, relative to equal, distribution condition, as reflected in the interactions between Pronoun, Variety, Distribution and Time.

In the analysis of the time-course of fixations to SUBJ (Appendix B) we found a main effect of Pronoun $(\beta=-0.05, p<.01)$ and an interaction between Pronoun and Time, whereby there were more and increasing fixations to SUBJ in the condition of null, relative to overt, pronouns. This effect was especially pronounced for EP (three-way interaction Pronoun:Time:variety).

Mean Fixations as a function of POvert 
Figure 7 shows the mean proportion of fixations to OBJ as a function of the probability of overt (relative to null) pronouns, computed for each participant and trial (P(Overt), see Analysis of Experiment 1 for details). It illustrates how participants made increasing fixations to the depicted object referent with decreasing probability of overt pronouns. Whereas this seems to happen especially for overt pronouns, the interaction between pronoun and POvert did not reach significance in the analysis regressing the mean fixations to OBJ against the predictors Pronoun, Variety, Distribution, and POvert, summarized in Table 4. However, POvert interacted significantly with Variety, whereby the less probable overt pronouns were (and the more likely null pronouns are), the more Brazilian participants fixated on the depicted object referent, across pronoun condition.

We found no effects of fixations to SUBJ (Appendix B) as a function of P(Overt).

[FIGURE 7 NEAR HERE]

[TABLE 4 NEAR HERE]

\section{Discussion}

Experiment 2 assessed the resolution of ambiguous overt and null pronouns in an online visual-world task, where eye fixations to depicted referents index pronoun resolution. Participants fixated more and increasingly the depicted object referent when the spoken sentence contained an overt pronoun, reflecting the object-bias interpretation of this pronominal form. More important, this was especially the case for Brazilian participants, and 
in an environment with an overall lower probability of overt pronouns, thereby replicating the main finding of Experiment 1. We interpret this result as additional evidence of an effect of pronoun probability on pronoun interpretation.

We also find that Brazilian participants increasingly associate both overt and null pronouns with an object referent, as the probability of overt pronouns decreases. This is consistent with Experiment 1, where BP comprehenders were more likely to choose object referents the more they had previously been presented with null pronouns, the pronoun type for which there is a strong subject-biased interpretation.

An additional Welch Two Sample t-test showed that the mean proportion of fixations to $\mathrm{OBJ}$ was not significantly different in the equal and the unequal distribution conditions, neither for BP $($ means $=0.24,0.24 ; 95 \%$ CIs $[-0.04,0.04])$ nor EP $($ means $=0.23,0.25 ; 95 \%$ CIs $[-0.06,0.01])$, suggesting that the adaptive behaviour might have been driven by prior statistical knowledge about the likelihood of speakers to refer to object and subject referents.

Note that Experiment 2 provides evidence from online processing, where pronoun resolution was less constrained in that participants' visual attention could be allocated not only to the two potential pronoun referents, but also to two additional visual entities. That is, in the visual-world task participants were not constrained, ultimately, to resolve the pronoun and, if they did, they were not obliged to choose an interpretation of the pronoun as referring back to one or the other possible referents (i.e., fixations to SUBJ and OBJ are not jointly exhaustive nor mutually exclusive). We believe that this is important evidence of pronoun resolution in an experimental environment that more closely resembles the linguistic environment where referring expressions can remain ambiguous. Moreover, we replicated the results of Experiment 1 in a paradigm that minimizes possible deliberate strategies whereby participants might have increasingly assigned object referents as they realized they had been 
assigning mostly subject referents, in an environment with a higher frequency of null pronouns. Importantly, our results were highly similar in our offline questionnaires and in the online visual-world experiment. This is even more notable since the offline questionnaire experiments used written materials, while stimuli in the visual-world experiment were spoken. We consider this as evidence for the robustness of our results and note that previously reported differences between online and offline patterns of resolution might reflect the lower sensitivity of the measures taken to reflect reference resolution (e.g., the acceptability judgments in Almor et al., 2017).

Below, we discuss more broadly the implications of the findings of our two experiments.

\section{General discussion}

In two experiments, we investigated the resolution of ambiguous overt and null pronouns towards subject and object referents in an experimental environment that manipulated the relative probabilities of the two pronominal forms. Building on prior work (e.g., Fine et al., 2013; Jaeger \& Snider, 2013), we expected that comprehenders would track and adapt to the statistics of the experiment. We found that participants resolved overt pronouns as coreferring with an object referent to a greater extent in an environment biased towards a lower probability of overt pronouns, compared to an environment where there was an (overall) equal probability of null and overt pronouns. That is, in face of an environment with unequally distributed pronominal forms, comprehenders changed their resolution preferences (i.e., their beliefs about the likelihood of referents given pronouns - the second hypothesis in the Introduction), rather than their assumptions about the overall likelihood of referencing a particular kind of referent (the first hypothesis). Moreover, we observed the same pattern of 
change as a function of finer-grained variations in pronoun probability, coding for the relative probabilities of overt and null pronouns at each point in the experimental session.

First, these results suggest that pronoun resolution is affected by the probability of pronominal forms. Previous research showed that the interpretation of a pronominal form is affected by the likelihood of potential referents to be re-mentioned (e.g., Rohde \& Kehler, 2014, where the likelihood of referents depended on verbs' semantics). In the current study, we controlled for the likelihood of referents while manipulating the probability of pronouns, and found that pronoun resolution is also affected by the likelihood of the pronominal form. Although probabilistic approaches to reference (e.g., Frank \& Goodman, 2012; Kehler et al., 2008) build on models, such as Bayesian inference, which appeal to the probability distributions not only of referents, but also of pronouns (and of pronouns over referents), no previous studies have investigated how pronoun probability affects interpretation. Our findings thus give further support to such approaches where statistical (distributional) information about referents and anaphoric expressions is combined in the inference process underlying pronoun resolution. This is also relevant evidence for broader theories of pronoun interpretation and use, as these appeal to the relations between alternative potential referents and alternative pronominal forms (e.g., Almor, 1999; Ariel, 1990, 1994; Arnold, 2001, 2008; Kehler et al., 2008). Our results are in line with evidence for the negative relation between forms' explicitness and referents' prominence but, crucially, identify a novel factor that can modulate the strength of such relation, pronoun probability, which shall be taken into consideration in quantitative and theoretical models of pragmatic inference. They suggest that the overall rate of references to each of two alternative referents can be a leading factor guiding interpretation, and that the direction of causality may be not only (as more often assumed) from interpretation to use, but also from use to interpretation. That is, it is not only the case that speakers choose an anaphoric expression guided by their knowledge about 
interpretation biases (which would remain constant), but also that comprehenders interpret those expressions depending on how (often) they were used.

Second, and more important, our results provide preliminary evidence for adaptation in pronoun resolution, by showing that comprehenders' behaviour changed depending on the statistics of the experimental context. This result is in itself a strong argument favouring probabilistic accounts to reference, as these assume that the result of interpretation is not a single referent but rather a variable estimate about the likelihood of each potential referent.

Through adaptation (Anderson, 1991), the cognitive processor builds up, and updates in face of new evidence, a probabilistic model of the environment. Such a probabilistic model is especially useful when the processor has to infer, under uncertainty, a category from a given cue. In the case of ambiguous pronouns, comprehenders have to infer what was the referent the speaker intended to mention by using a particular pronominal form. The probabilistic model of the environment that is relevant for pronoun resolution might make reference to several events with different probabilities of occurrence. In the current study, we focused on the marginal probabilities of forms (that is, the relative probabilities of overt and null pronouns, regardless of referents). As we saw in the Introduction, these probabilities relate in particular ways to the conditional probabilities of referents given pronominal forms, that is, to resolution preferences. In particular, changing the probabilities of overt and null pronouns results either in changes in the probabilities of referents, while keeping resolution preferences constant, or in changes in resolution preferences, while keeping the probabilities of referents constant (or both).

In our experiments, we manipulated experimentally the overall probability of two pronominal forms, and found that this manipulation had an impact on how participants resolved pronouns. The increased object-biased resolution of pronouns (especially overt pronouns, but also across pronoun type, for BP) with decreasing rate of overt pronouns 
suggests that the processor adapted to an environment where object referents would become less likely, if interpretation biases would not change (as overt pronouns have a stronger object-biased interpretation than null pronouns). The processor inferred that the speaker did not want to make fewer references to object antecedents and, therefore, adapted by increasing the object-bias in interpretation. We suggest that this is consistent with the idea of an optimization of the process whereby pronouns signal specific referents, under a rational adaptation approach. Optimizing the inference process rationally requires that this process has a goal (Anderson, 1991). The more immediate goal of any rational adaptation process might be to minimize the error in predicting categories from cues in the environment (i.e., reduce uncertainty, Jaeger \& Snider, 2013, Kleinschmidt \& Jaeger, 2015). In the particular case of ambiguous pronouns, the ultimate goal of resolution (and pronoun use) might be to have cues signalling the intention of referring to one or another referent (as more or less explicitly assumed in many theories of pronoun resolution; see Introduction). In other words, language users should benefit from, on the one hand, having the possibility of referring to different referents and, on the other hand, having different cues that reliably signal their referring intentions. If one of two cues became progressively less likely, references to the referent signalled by that cue would also become less likely, if the interpretation of the cue remained unchanged. Ultimately, the use of only one pronominal form would prevent its use as a good cue to signal the intention of referring to one or another referent, as that form would be the only one available to signal all referents ${ }^{\mathrm{xi}}$.

We thus hypothesize that adaption in pronoun resolution is rational (Anderson, 1991), in that it seems to have the goal of maintaining the possibility for comprehenders to interpret pronouns as co-referring with one or another alternative referent, to an approximately equal extent, across variations in the relative frequencies of pronominal forms. In other words, the way participants resolve pronouns would be driven by their prior knowledge of how likely it 
is that speakers make references to subject and object referents. Supporting this hypothesis, we found that the mean answer (Experiment 1), and the mean proportion of fixations to OBJ (Experiment 2), were not significantly different between distribution conditions, in BP. However, in EP, there were fewer object choices (and, concurrently, more subject choices) in the unequal, compared to the equal distribution conditions in Experiment 1. It is theoretically possible that our experimental manipulation did not provide a statistical environment that diverged enough from the language environment in EP, and that thus EP comprehenders' adaptation did not achieve its goal. However, our data do not allow us to draw this conclusion, and further research is needed in support of this hypothesis. For example, if some degree of variation in the statistics of the environment is needed in order to observe adaptation, we might expect to observe stronger adaptation if EP comprehenders would be faced with an environment with a higher probability of overt, relative to null pronouns, i.e., where the statistics would deviate from the ones they could learn from experience within the language. In line with our hypothesis of rational adaptation, if the processor would try to avoid reduction in the number of references to subject referents, in such condition, EP comprehenders should adapt by increasingly interpreting overt pronouns as co-referring with subject referents (and/or by increasingly interpreting null pronouns as co-referring with subject referents), compared to an equal distribution condition. Such result would also provide important corroborating evidence of an adaptive process that integrates prior (i.e., the language) with current (i.e., in the experimental context) statistical knowledge, and that can underlie previously observed differences in pronoun resolution across languages (e.g., Filiaci et al., 2013) or varieties (e.g., Luegi et al., 2014).

In sum, we believe that, by framing pronoun resolution under the adaptation framework, the current study provides new insights that are relevant for the explanatory accounts of reference and, in particular, pronoun resolution. 
Moreover, we think that our study adds to previous research on adaptation in language processing: On one hand, our study joins a growing body of literature on learning and adaptation in the domains of speech (e.g., Clayards, Tanenhaus, Aslin, \& Jacobs, 2008; Vroomen et al., 2007; Kleinschmidt \& Jaeger, 2015), syntactic (e.g., Fine et al., 2013; Jaeger \& Snider, 2013; Kaschak \& Glenberg, 2004), and lexical processing (Yildirim et al., 2016). On the other hand, and importantly, we add to previous research by providing evidence for an adaptation process that does not restrict to tracking and learning statistical information that is explicitly given in the experimental context, but uses that information to make more complex, interpretational, inferences: Whereas, in previous studies, comprehenders' behaviour assessed some measure that directly reflected the statistical environment that was manipulated (e.g., reading speed of syntactic structures reflecting learning of the manipulated frequency of syntactic structures; conditional probability of phoneme category given a phonetic cue reflecting learning the manipulation of the relevant conditional probabilities), in the present work we assessed a behaviour (interpretation) that related only indirectly with the statistical manipulation (of pronoun probability). That is, in our study, comprehenders tracked the statistics of pronominal forms but were not asked to guess about those probabilities, but instead about the conditional probabilities of referents given pronouns. This means that the statistics of a novel environment can be learned, with that knowledge being further used to compute related (but not explicitly presented) statistics.

Before concluding with a few open questions for future research, it is important to address one final point: Given that our major finding is that participants adapt to the pronoun probabilities in their environment and that this adaptation affects resolution, it could be argued that exposure to pronoun probabilities in an L2 would also have an effect on the L1. Recall that our experiment 2 was run in Paris, where participants were in a situation of immersion in a foreign (non-null-subject) language, namely French. While we agree that, 
ideally, data collection for experiment 2 should have taken place in Portugal and Brazil, this was, unfortunately, not an option. We do not believe, however, that this methodological limitation had any major effects on our results for various reasons. First and most important, the results of experiment 2 are in line with those of experiment 1, for which testing was conducted in Portugal and Brazil in our participants' native environments. Moreover, our results for the EP group are also in line with previous studies done in Portugal on EP: Luegi (2012), for example, observed similar interpretation preferences for null and overt pronouns to those elicited in our EP group. Second, if exposure to (overt) pronouns in French had influenced our results, we would predict different patterns of interpretation from those elicited in our study. In particular, EP speakers should have shown a less clear preference for the object antecedent with overt pronouns, and no effect or a bigger preference for the subject antecedent with overt pronouns should have been observed in the BP group. Crucially, however, our results show that, in the equal distribution condition, both groups behave differently, in line with differences attested in previous studies (i.e., a general preference for the subject with null pronouns in both EP and BP, and a clear object preference for overt pronouns in $\mathrm{EP}$, while no clear preference in $\mathrm{BP}$ ), and that, in the unequal distribution condition, preferences in both groups change regarding overt pronoun resolution, especially in the BP group, in line with our initial predictions. Third, most of our participants were residing at the student residences "Maison du Portugal" and "Maison du Brésil" at the time of testing, where they were exposed to their respective varieties of Portuguese on a daily basis through interaction with other fellow Portuguese and Brazilian students. Finally, previous studies that argue for effects of the L2 in the domain of pronoun interpretation in the L1 do so in participants that have been living in the L2-speaking country for five years or more based on their lack of online sensitivity to pronoun resolution biases. For example, Chamorro, Sorace and Sturt (2015) investigated attrition effects in null and overt pronoun interpretation 
preferences in Spanish in three different groups exposed to L2 English: a group of monolingual speakers who had recently arrived in the UK (average length of residence of 7.9 weeks), a group of attriters who had resided in the UK for 5 years or more (average length of residence of 7 years), and a group exposed attriters who had also resided in the UK for 5 years or more, but had been exposed to Spanish for an extended period of time at the time of testing. The results of their eye-tracking during reading experiment revealed that, while the monolingual and the exposed attriters were reliably sensitive to pronoun mismatches (i.e., overt pronoun when null pronoun is appropriate or null pronoun where overt pronoun is appropriate) very early on, resulting in a significant interaction between pronoun and antecedent types, the attriters did not show any evidence for this interaction in any measure, indicating a lack of online sensitivity to the pronoun mismatch. Crucially, most of our participants of experiment 2 had been living in France for less than five years at the time of testing $^{\mathrm{xii}}$ and, importantly, the reliable interactions elicited in both groups in our experiment can be taken as evidence against any effects of attrition in L1 pronoun interpretation in our participants.

The present work takes a first step towards future investigation of pronoun resolution under the adaptation and learning framework. One question for further research concerns whether and how comprehenders could adapt to variations in other probabilistic knowledge about pronouns, referents, and their relationships. For example, would comprehenders adapt to conditional probabilities of forms given referents (i.e., pronoun use biases, which are assumed to affect resolution in Kehler et al.'s (2008) proposal) during an experimental session? How would resolution change in an environment where the probabilities of Referents diverge from the ones experienced in the language? In sum, what kind of probabilistic knowledge is relevant for pronoun resolution, and how is prior (i.e., before the 
experiment) knowledge integrated with recent linguistic experience (i.e., along an experimental session)?

Another question concerns how that knowledge is updated iteratively, based on each new piece of evidence, i.e., after each new observation. Our finding that pronoun resolution was modulated by variations in pronoun probability at any given point in the experimental session highlights the incremental nature of adaptation: Comprehenders can update, given each new piece of evidence concerning pronoun probability, their beliefs about the likelihood of referents given pronominal forms (something that is not captured by the betweenparticipants predictor Distribution, coding overall, i.e., across trials, pronoun resolution). One way of addressing this issue is to develop computational models that can provide clear quantitative predictions about how comprehenders integrate prior (i.e., before the experiment) with recent linguistic experience, which can be evaluated against the behavioural data. Among other, these could be implemented in the form of Bayesian belief update models, in line with recent work modeling the adaptive process, for example, in syntactic processing (Kleinschmidt, Fine, \& Jaeger, 2012), or in speech perception (Kleinschmidt \& Jaeger, 2015), and as predicted by previously proposed probabilistic accounts of pronoun resolution (Kehler et al., 2008).

We believe that these are important questions that deserve further investigation, combining behavioural evidence such as the one provided by the current study, corpus studies providing reliable estimates of pronouns and referents probabilities, and computational models that could provide clear predictions about how prior knowledge is integrated within current statistics, and how, given any new piece of evidence, comprehenders update their beliefs about the relevant statistics of the environment and use these to guide pronoun interpretation. 


\section{Conclusion}

Our results add to previous proposals instantiating pronoun resolution as a probabilistic problem by showing that interpretation is not only affected by the probability of referents, but also by the probability of pronouns. More important, they show that comprehenders adapt to the probabilities of pronominal forms in a new environment, and call for future investigation of pronoun resolution under the framework of adaptation, following recent work on other domains of language processing. 
ADAPTATION IN PRONOUN RESOLUTION

\section{Appendix A}

Experimental items: Differences in BP sentences are indicated within parenthesis.

1 A florista sossegou (tranquilizou) a peixeira no mercado quando Ø/ela divulgou os resultados do exame.

The florist calmed down the fishmonger at the market when Ø/she revealed the results of the exam.

2 O ginasta treinou o nadador no clube quando Ø/ele desistiu do campeonato regional.

The gymnast trained the swimmer in the club when Ø/he gave up the regional championship.

3 A agente provocou a testemunha na esquadra (delegacia) quando Ø/ela corrigiu o depoimento sobre o crime.

The agent provoked the witness in the police station when Ø/she corrected the testimony about the crime.

$4 \mathrm{O}$ arquiteto ensinou (criticou) o empreiteiro no gabinete quando $\varnothing /$ ele indicou os defeitos da construção.

The architect taught/criticized the contractor in the cabinet when Ø/he pointed out the flaws of the building.

5 A dentista insultou a secretária no consultório quando Ø/ela revelou as imagens do assalto.

The dentist insulted the secretary in the office when Ø/she revealed the images of the robbery. 
ADAPTATION IN PRONOUN RESOLUTION

6 O mecânico aconselhou o engenheiro na oficina quando Ø/ele desmontou o protótipo de fórmula 1 (do veículo).

The mechanic advised the engineer in the garage when Ø/he disassemble the formula 1 prototype.

7 A costureira ignorou a noiva no ateliê quando Ø/ela atendeu o telefone (celular) durante a prova (o ajuste).

The dressmaker ignored the bride in the studio when Ø/she picked up the cell phone during the dress fitting.

8 O atleta consultou o ortopedista no hospital quando Ø/ele regressou da viagem a (para Itália).

The athlete consulted the orthopaedist at the hospital when Ø/he returned from the trip to Italy.

9 A empregada (professora) abraçou a enfermeira no restaurante quando Ø/ela anunciou o noivado da filha.

The maid hugged the nurse at the restaurant when Ø/she announced the engagement of her daughter.

$10 \mathrm{O}$ aluno encontrou o professor na residência quando Ø/ele adoeceu com papeira (caxumba) nas férias.

The student found the teacher at the residence when Ø/he fell ill with mumps during the vacation.

11 A treinadora orientou a patinadora no ginásio quando Ø/ela adquiriu os acessórios de (do) treino. 
ADAPTATION IN PRONOUN RESOLUTION

The coach guided the roller skater in the gym when Ø/she purchased the training accessories.

$12 \mathrm{O}$ domador empurrou o mágico no circo quando Ø/ele acendeu uma fogueira junto à jaula.

The tamer pushed the magician in the circus when Ø/he ignited a fire by the cage.

13 A cabeleireira acalmou a esteticista no salão quando escutou (repetiu) as notícias na rádio.

The hairdresser calmed the esthetician in the hair salon when Ø/she listened to the news on the radio.

$14 \mathrm{O}$ pedreiro abordou o carpinteiro na obra quando Ø/ele arrumou os materiais no armário.

The mason approached the carpenter in the construction site when Ø/he packed up the materials in the closet.

15 A pianista esperou a violinista no hotel quando Ø/ela aceitou o convite para o concerto. The pianist waited for the violinist at the hotel when Ø/she accepted the invitation to the concert

16 O capitão encorajou o marinheiro no porto quando Ø/ele recolheu as amarras do navio.

The captain encouraged the sailor in the harbour when Ø/he picked up the moorings of the ship.

17 A fotógrafa saudou (parabenizou) a jornalista na redação quando Ø/ela terminou a reportagem sobre as cheias.

The photographer greeted the journalist at the newsroom when Ø/she finished the report on the floods.

$18 \mathrm{O}$ cientista contrariou o médico na palestra quando Ø/ele confirmou a evidência científica. 
ADAPTATION IN PRONOUN RESOLUTION

The scientist contradicted the doctor at the conference when Ø/he confirmed the scientific evidence.

19 A locutora interrompeu a cozinheira no programa quando Ø/ela irrompeu (apareceu) pelo (no) palco secundário.

The radio newscaster interrupted the cook in the program when Ø/she burst through the secondary set.

20 O advogado ameaçou o jornalista no estúdio quando Ø/ele retornou do tribunal Constitucional.

The lawyer threatened the journalist in the studio when Ø/he returned from the Constitutional Court.

21 A médica examinou a desportista (atleta) no estágio quando Ø/ela detetou (percebeu) as contusões de esforço.

The doctor examined the athlete during the internship when Ø/she detected (perceived) the exertional concussions.

$22 \mathrm{O}$ guarda protegeu o preso na cadeia quando Ø/ele almoçou no refeitório disfarçadamente.

The guard protected the prisoner in jail when Ø/he ate lunch in the cafeteria covertly.

$23 \mathrm{O}$ bombeiro desmentiu o militar no quartel quando Ø/ele escreveu o relatório do treino.

The firefighter contradicted the soldier in the barracks when Ø/he wrote the training report.

24 A bailarina confrontou (observou) a professora (empregada) no parque quando Ø/ela descreveu o acidente rodoviário. 
ADAPTATION IN PRONOUN RESOLUTION

The dancer confronted (observed) the teacher (maid) in the park when Ø/she described the road accident.

$25 \mathrm{O}$ segurança surpreendeu o assaltante no banco quando Ø/ele encontrou o diamante escondido.

The security guard surprised the burglar in the bank when Ø/he found the hidden diamond.

26 A telefonista defendeu a secretária no escritório quando Ø/ela explicou (assumiu) o equívoco a todos.

The operator defended the secretary in the office when Ø/she explained (assumed) the mistake to all.

$27 \mathrm{O}$ empresário contratou o contabilista (contador) na empresa quando Ø/ele alterou o projeto de investimento.

The businessman hired the accountant in the company when Ø/he changed the investment project.

28 A hospedeira (aeromoça) seguiu a atriz no jardim quando Ø/ela passeou a cadela labrador (vira-lata).

The flight attendant followed the actress in the garden when Ø/she walked the retriever (mutt).

29 O jardineiro acusou o agricultor no encontro quando Ø/ele relatou os problemas ocorridos.

The gardener accused the farmer at the meeting when Ø/he reported the problems.

$30 \mathrm{O}$ guitarrista alegrou o vocalista no teatro quando Ø/ele assistiu ao ensaio da banda. 
ADAPTATION IN PRONOUN RESOLUTION

The guitarist cheered the vocalist in the theater when Ø/he watched the rehearsal of the band.

31 A violoncelista alojou a maestrina (regente) na fazenda quando Ø/ela preparou a digressão (o programa) internacional.

The cellist housed the conductor in the farm when Ø/she prepared the international tour.

$32 \mathrm{O}$ agente (policial) esclareceu (desarticulou) o condutor na autoestrada (rodovia) quando Ø/ele exibiu o documento de identificação.

The police officer clarified (disarmed) the driver on the motorway when Ø/he displayed the identification document. 
ADAPTATION IN PRONOUN RESOLUTION

\section{Appendix B}

\section{Fixations to SUBJ}

Figure B1 plots the time-course of proportion of fixations to SUBJ along $1500 \mathrm{~ms}$ from the offset of when and Figure B2 shows the mean fixations to SUBJ in that time-window as a function of POvert. Tables B1 and B2 present the fitted models.

[FIGURE B1 NEAR HERE]

[TABLE B1 NEAR HERE]

[FIGURE B2 NEAR HERE]

[TABLE B2 NEAR HERE] 
ADAPTATION IN PRONOUN RESOLUTION

\section{Acknowledgements}

We thank Heather Burnett and three anonymous reviewers for comments on an earlier version of this manuscript. Any remaining errors are our own. We also thank Moreno I. Coco for generously providing the $R$ code used in Experiment 2 data pre-processing; Muriel Assmann, for her help with the creation of BP materials, and Doriane Gras for technical help with Experiment 1.

This work was supported by the French National Research Agency (ANR-10-LABX0083) and partially supported by the CAPES Foundation (under Grant 0628-14-0 awarded to ECS) and by Fundação para a Ciência e Tecnologia (under Grant SFRH/BPD/84138/2012 awarded to PL). 


\section{References}

Almor, A. (1999). Noun phrase anaphora and focus: The informational load hypothesis. Psychological Review, 106, 748-765. doi:10.1037/ 0033-295X.106.4.748

Almor, A., de Carvalho Maia, J., Cunha Lima, M.L., Vernice, M., \& Gelormini-Lezama, C. (2017). Language processing, acceptability, and statistical distribution: a study of null and overt subjects in brazilian portuguese. Journal of Memory and Language, 92, 98113. doi:10.1016/j.jml.2016.06.001

Anderson, J. R. (1991). The adaptive nature of human categorization. Psychological Review, 98(3), 409-429. doi: 10.1037//0033-295X.98.3.409

Ariel, M. (1990). Accessing noun-phrase antecedents. London, England: Routledge. doi: $10.4324 / 9781315857473$

Ariel, M. (1994). Interpreting anaphoric expressions: a cognitive versus a pragmatic approach. Journal of Linguistics, 30, 3-42. doi: https://doi.org/10.1017/S0022226700016170

Arnold, J. E. (2001). The effect of thematic roles on pronoun use and frequency of reference continuation. Discourse Processes, 31, 137-162. doi:10.1207/S15326950DP3102_02

Arnold, J. E. (2008). Reference production: Production-internal and addressee-oriented processes. Language and Cognitive Processes, 23:4, 495-527. doi: $10.1080 / 01690960801920099$

Arnold, J. E., Eisenband, J. G., Brown-Schmidt, S., \& Trueswell, J. C. (2000). The rapid use of gender information: Evidence of the time course of pronoun resolution from eyetracking. Cognition, 76(1), B13:B26. doi:10.1016/S0010-0277(00)00073-1. 
Barr, D. J., Levy, R., Scheepers, C., \& Tily, H. J. (2013). Random effects structure for confirmatory hypothesis testing: Keep it maximal. Journal of Memory and Language, 68 (3), 255-278. doi: 10.1016/j.jml.2012.11.001

Barbosa, P., Duarte, M. E. L., \& Kato, M. A. (2005). Null subjects in European and Brazilian Portuguese. Journal of Portuguese Linguistics, 4 (2), 11-52. doi: http://doi.org/10.5334/jpl.158

Bates, D., Maechler, M., Bolker, B., Walker, S. (2015). Fitting linear mixed-effects models using lme4. Journal of Statistical Software, 67(1), 1-48. doi: 10.18637/jss.v067.i01

Boland, J. (2004). Linking eye movements to sentence comprehension in reading and listening. In M. Carreiras \& C. Clifton, Jr. (Eds.), The on-line study of sentence comprehension (pp. 51-76). New York: Psychology Press.

Carminati, M. N. (2002). The processing of Italian subject pronouns (Unpublished doctoral dissertation). Retrieved from http://scholarworks.umass.edu/dissertations/AAI3039345

Chamorro, G., Sorace, A., \& Sturt, P. (2015). What is the source of L1 attrition? The effect of recent L1 re-exposure on Spanish speakers under L1 attrition. Bilingualism: Language and Cognition, Available on CJO 2015 doi:10.1017/S1366728915000152

Chang, F., Dell, G. S., \& Bock, K. (2006) Becoming syntactic. Psychological Review, 113, 234-72.

Clayards, M., Tanenhaus, M., Aslin, R., \& Jacobs, R. (2008). Perception of speech reflects optimal use of probabilistic speech cues. Cognition, 108(3), 804-809. doi:10.1016/j.cognition.2008.04.004 
Coco, M. I., Keller, F., \& Malcom, G. L. (2015). Anticipation in real-world scenes: The role of visual context and visual memory. Cognitive Science, 40 (8),1995-2024. doi: $10.1111 / \operatorname{cogs} .12313$

Colonna S., Schimke S. \& Hemforth B. (2015). Different effects of focus in intra- and intersentential pronoun resolution in German. Language, Cognition and Neuroscience, 30(10), 1306-1325. doi: 10.1080/23273798.2015.1066510

Colonna, S., Schimke, S., Vincent, C., de la Fuente, I., \& Hemforth, B. (2016). Influence du contexte expérimental sur l'interprétation des anaphores pronominales en français. SHS Web of Conferences, 27, 10004. http://dx.doi.org/10.1051/shsconf/20162710004

Corrêa, L. M. S. (1998) Acessibilidade e paralelismo na interpretação do pronome sujeito e o contraste pro/pronome em português. DELTA, 14 (2), 95-329. doi : 10.1590/S010244501998000200002

Costa, M. A., Faria, I. H., \& Kail, M. (2004). Semantic and syntactic cues' interaction on pronoun resolution in European Portuguese. In A. Branco, T. McEnery, \& R. Mitkov (Eds), DAARC 2004, 5th Discourse Anaphora Resolution Colloquium. Proceedings. (pp. 45-50). Lisbon: Ed. Colibri.

Costa, A., Faria, I., \& Matos, G. (1998). Ambiguidade referencial na identificação do sujeito em estruturas coordenadas. Textos seleccionados do XIII Encontro Nacional da Associação Portuguesa de Linguística, Lisboa, Colibri (173-188). Retrieved from http://www.apl.org.pt/actas/xiii-encontro-nacional-da-associacao-portuguesa-delinguistica.html 
Courville, A. C., Daw, N. D., \& Touretzky, D. S. (2006). Bayesian theories of conditioning in a changing world. Trends in Cognitive Sciences, 10(7), 294-300. doi:10.1016/j.tics.2006.05.004

Crocker, M. W., \& Brants, T. (2000). Wide-coverage probabilistic sentence processing. Journal of Psycholinguistic Research, 29 (6), 647-669. doi: 10.1023/A: 1026560822390

de la Fuente, I., \& Hemforth, B (2013). Effects of Clefting and Left-Dislocation on Subject and Object Pronoun Resolution in Spanish. In Selected Proceedings of the 16th Hispanic Linguistics Symposium, ed. Jennifer Cabrelli Amaro et al., 27-45. Somerville, MA: Cascadilla Proceedings Project. www.lingref.com, document \#2923.

Demberg, V., \& Keller, F. (2008). Data from Eye-tracking Corpora as Evidence for Theories of Syntactic Processing Complexity. Cognition, 109 (2), 193-210.

Drummond, A. (2013). Ibex farm. Online server: http://spellout.net/ibexfarm.

Duarte, M. E. L. (1993). Do pronome nulo ao pronome pleno: a trajetória do sujeito no português do Brasil. In I. Roberts \& M. A Kato (Eds). Português Brasileiro: Uma viagem diacrônica (Homenagem a Fernando Tarallo). Campinas: Editora da UNICAMP (pp. 107-128).

Duarte, M. E. L. (2000). The loss of the 'Avoid Pronoun' principle in Brazilian Portuguese. In M. A. Kato \& E. V. Negrão (Eds.), The Null Subject Parameter in Brazilian Portuguese. Frankfurt-Madrid: Vervuert-IberoAmericana. (pp. 17-36).

Fine, A. B., \& Jaeger, T. F. (2013). Evidence for implicit learning in syntactic comprehension. Cognitive Science, 37(3), 578-91. doi:10.1111/cogs.12022 
Fine, A. B., Jaeger, T. F., Farmer, T. A., \& Qian, T. (2013). Rapid expectation adaptation during syntactic comprehension. PLOS ONE, 8, e77661. doi: 10.1371/journal.pone.0077661

Filiaci, F., Sorace, A., \& Carreiras, M. (2013). Anaphoric biases of null and overt subjects in Italian and Spanish: a cross-linguistic comparison. Language, Cognition and Neuroscience, 29 (7), 1-19. doi: 10.1080/01690965.2013.801502

Frank, M. C., \& Goodman, N. D. (2012). Predicting pragmatic reasoning in language games. Science, 336, (6084), 998. doi: 10.1126/science.1218633

Fukumura, K, \& van Gompel, R. P. G. (2015). Effects of order of mention and grammatical role on anaphor resolution. Journal of Experimental Psychology: Learning, Memory, and Cognition, 41 (2), 501-525. doi : 10.1037/xlm0000041

Garrod, S., \& Sanford, A. J. (1982). The mental representation of discourse in a focused memory system: Implications for the interpretation of anaphoric noun phrases. Journal of Semantics, 1, 21-41. doi: 10.1093/jos/1.1.21

Gernsbacher, M. A., \& Hargreaves, D. J. (1988). Accessing sentence participants: The advantage of first mention. Journal of Memory and Language, 27, 699-717. doi:10.1016/0749-596X(88)90016-2

Gordon, P. C., Grosz, B. J., \& Gilliom, L. A. (1993). Pronouns, names, and centering of attention is discourse. Cognitive Science, 17, 311-347. doi:10.1207/s15516709cog1703_1

Gundel, J. K., Hedberg, N., \& Zacharski, R. (1993). Cognitive status and the form of referring expressions in discourse. Language, 69, 274-307. doi : 10.2307/416535 
Huettig, F., Rommers, J., \& Meyer, A. S. (2011). Using the visual world paradigm to study language processing: A review and critical evaluation. Acta Psychologica, 137, 151171. doi:10.1016/j.actpsy.2010.11.003

Jaeger, T. F. (2008). Categorical data analysis: Away from ANOVAs (transformation or not) and towards logit mixed models. Journal of Memory and Language, 59(4), 434-446. doi: $10.1016 /$ j.jml.2007.11.007

Jaeger, T. F., \& Snider, N. E. (2013). Alignment as a consequence of expectation adaptation: Syntactic priming is affected by the prime's prediction error given both prior and recent experience. Cognition, 127, 57-83.

Järvikivi, J., Van Gompel, R. P. G., Hyönä, J., \& Bertram, R. (2005). Ambiguous pronoun resolution: Contrasting the first-mention and subject preference accounts. Psychological Science, 16, 260-264. doi:10.1111/j.0956-7976.2005.01525.x

Jurafsky, D. A (1996). Probabilistic model of lexical and syntactic access and disambiguation. Cognitive Science, 20, 137-194. doi: 10.1207/s15516709cog2002_1

Kaiser, E. (2016). Discourse-level Processing. In P. Knoeferle, P. Pyykkönen-Klauck \& M. W. Crocker (eds.), Visually Situated Language Comprehension (pp.151-184). John Benjamins.

Kaiser, E., \& Trueswell, J. C. (2008). Interpreting pronouns and demonstratives in Finnish: Evidence for a form-specific approach to reference. Language and Cognitive Processes, 23, 709 -748. doi:10.1080/01690960701771220

Kamide, Y., Altmann, G., \& Haywood, S. (2003). The time-course of prediction in incremental sentence processing: Evidence from anticipatory eye movements. Journal of Memory and Language, 49(1), 133-156. doi: 10.1016/S0749-596X(03)00023-8 
Kaschak, M., \& Glenberg, A. (2004). This construction needs learned. Journal of Experimental Psychology: General, 133 (3), 450-467. doi: 10.1037/00963445.133.3.450

Kehler, A., Kertz, L., Rohde, H., \& Elman, J. L. (2008). Coherence and coreference revisited. Journal of Semantics, 25, 1-44. doi:10.1093/jos/ ffm018

Kehler, A., Rohde, H. (2013). A probabilistic reconciliation of coherence-driven and centering-driven theories of pronoun interpretation. Theoretical Linguistics, 39, 1-37. doi: http://dx.doi.org/10.1515/tl-2013-0001

Kleinschmidt, D. F., Fine, A. B., \& Jaeger, T. F. (2012). A belief-updating model of adaptation and cue combination in syntactic comprehension. Proceedings of the 34th Annual Conference of the Cognitive Science Society. Sapporo, Japan.

Kleinschimdt, D. F., \& Jaeger, T. F. (2015). Robust speech perception: recognize the familiar, generalize to the similar, and adapt to the novel. Psychol. Rev., 122 (2), 148203. doi: $10.1037 / \mathrm{a} 0038695$.

Kolmogorov, A. N. (1956). Foundations of the theory of probability. New York: Chelsea.

Levy, R. (2008). Expectation-based syntactic comprehension. Cognition, 106, 1126:1177. doi: 10.1016/j.cognition.2007.05.006

Luegi, P. (2012). Processamento de sujeitos pronominais em Português: efeito da posição structural dos antecedents. PhD dissertation. University of Lisbon.

Luegi, P., Costa, A., \& Maia, M. (2014). Processamento e interpretação de sujeitos nulos e plenos em português Europeu e português do Brasil. Cadernos de Letras da UFF, 49, 67-88 
Metzing, C., \& Brennan, S. E. (2003). When conceptual pacts are broken: Partner-specific effects on the comprehension of referring expressions. Journal of Memory and Language, 49, 201-213. doi: 10.1016/S0749-596X(03)00028-7.

Mirman, D., Dixon, J. A., \& Magnuson, J. S. (2008). Statistical and computational models of the visual world paradigm: Growth curves and individual differences. Journal of Memory and Language, 59 (4), 475-494. doi: 10.1016/j.jml.2007.11.006

Nelson, W. W., \& Loftus, G. R. (1980). The functional visual field during picture viewing. Journal of Experimental Psychology: Human Learning and Memory, 6, 391-399. doi: 10.1037/0278-7393.6.4.391

R Development Core Team (2008). R: A language and environment for statistical computing. R Foundation for Statistical Computing, Vienna, Austria. ISBN 3-900051-07-0, URL https://www.r-project.org/

Rohde, H., \& Kehler, A. (2014). Grammatical and information-structural influences on pronoun production. Language, Cognition and Neuroscience, 29, (8), 912-927. doi: http://dx.doi.org/10.1080/01690965.2013.854918

Rumelhart, D., Hinton, G., \& Williams, R. (1986). Learning representations by backpropagating errors. Nature, 323(6088), 533-536.

Sanford, A. J., Sturt, P., Morrow, L. I., Moxey, L. M., \& Emmott, C. (2004). Production and comprehension measures in assessing plural object formation. In: Carreiras, M. and Clifton, C. (eds.) The On-Line Study of Sentence Comprehension: Eyetracking, ERPs, and Beyond. Psychology Press: New York, USA, pp. 151-167. 
Tanenhaus, M. K., Spivey-Knowlton, M. J., Eberhard, K. M., \& Sedivy, J. C. (1995). Integration of visual and linguistic information in spoken language comprehension. Science, 268, 1632-1634. doi: 10.1126/science.7777863

Teixeira, E. N., Fonseca, M. C. M., \& Soares, M. E. (2104). Resolução do pronome nulo em Português Brasileiro: Evidência de movimentação ocular. Veredas, 18 (1), 281-301.

Tily, H. \& Piantadosi, S. (2009). Refer efficiently: Use less informative expressions for more predictable meanings. In Proceedings of the workshop on the production of referring expressions: Bridging the gap between computational and empirical approaches to reference.

Vonk, W., Hustinx, L. G. M. M., \& Simons, W. H. G. (1992). The use of referential expressions in structuring discourse. Language and Cognitive Processes, 7(3), 301333. doi:10.1080/01690969208409389

Vroomen, J., van Linden, S., de Gelder, B., \& Bertelson, P. (2007). Visual recalibration and selective adaptation in auditory-visual speech perception: Contrasting build-up courses. Neuropsychologia, 45 (3), 572-7. doi: 10.1016/j.neuropsychologia.2006.01 .031

Yildirim, I., Degen, J., Tanenhaus, M. K., \& Jaeger, T. F. (2016). Talker-specificity and adaptation in quantifier interpretation. Journal of Memory and Language, 87, 128143. doi: https://doi.org/10.1016/j.jml.2015.08.003 


\section{Tables}

Table 1. Hypothetical conjoint and marginal probabilities for the co-occurrence of the attributes Referent and Form. (The corresponding conditional probabilities of Referents given Forms are within parentheses).

\begin{tabular}{|c|c|c|c|}
\hline \multirow[b]{2}{*}{ Referent } & \multicolumn{2}{|c|}{ Form } & \multirow{2}{*}{$\begin{array}{c}\text { Marginal } \\
\text { (Ref) }\end{array}$} \\
\hline & Null & Overt & \\
\hline Obj & $\begin{array}{l}p\left(\text { Subj}^{\wedge} \text { Null }\right)=0.4 \\
(p(\text { Subj } \mid \text { Null })=0.8) \\
p\left(\mathrm{Obj}^{\wedge} \text { Null }\right)=0.1 \\
(p(O b j \mid \text { Null })=0.2)\end{array}$ & $\begin{array}{l}p(\text { Subj^Overt })=0.1 \\
p(\text { Subj|Overt })=0.2) \\
p(\text { Obj^Overt })=0.4 \\
p(\text { Obj } \mid \text { Overt })=0.8\end{array}$ & $\begin{array}{l}0.5 \\
0.5\end{array}$ \\
\hline $\begin{array}{c}\text { Marginal } \\
\text { (Form) }\end{array}$ & 0.5 & 0.5 & \\
\hline
\end{tabular}


Table 2. Experiment 1: Summary of the model fitted to the binary responses (object, 1, vs. subject, 0). Predictors are Pronoun, Variety, Distribution, and POvert.

Z

Predictors

Estimate $\mathrm{SE}$ value $\operatorname{Pr}(>|\mathrm{z}|)$

\begin{tabular}{|c|c|c|c|c|c|}
\hline (Intercept) & -0.48 & 0.14 & -3.45 & $<.01$ & $* * *$ \\
\hline pronoun $[\mathrm{N},-0.4 ; 0,0.6]$ & 2.50 & 0.33 & 7.53 & $<.01$ & $* * *$ \\
\hline variety $[\mathrm{BP},-0.5 ; \mathrm{EP}, 0.5]$ & 0.56 & 0.27 & 2.10 & 0.04 & * \\
\hline distribution [Equal,-0.5; Unequal, 0.5 ] & 0.19 & 0.27 & 0.71 & 0.48 & \\
\hline POvert [-0.38-0.62] & -0.09 & 0.56 & -0.17 & 0.87 & \\
\hline pronoun:POvert & 1.23 & 1.20 & 1.02 & 0.31 & \\
\hline variety:POvert & 1.59 & 1.08 & 1.47 & 0.14 & \\
\hline distribution:POvert & 0.55 & 1.10 & 0.50 & 0.62 & \\
\hline pronoun:variety & 1.14 & 0.62 & 1.83 & $\mathbf{0 . 0 7}$ & . \\
\hline pronoun:distribution & 1.36 & 0.65 & 2.11 & 0.04 & $*$ \\
\hline variety:distribution & 0.40 & 0.53 & 0.75 & 0.45 & \\
\hline pronoun:variety:POvert & -4.57 & 2.34 & -1.95 & 0.05 & . \\
\hline pronoun:distribution:POvert & 0.07 & 2.41 & 0.03 & 0.98 & \\
\hline variety:distribution:POvert & 2.48 & 2.18 & 1.14 & 0.26 & \\
\hline pronoun:variety:distribution & -2.55 & 1.26 & -2.03 & 0.04 & $*$ \\
\hline pronoun:variety:distribution:POvert & -0.76 & 4.68 & -0.16 & 0.87 & \\
\hline
\end{tabular}

Signif. codes: 0 '***’ 0.001 '**' 0.01 '*’ 0.05 '? 0.1 ' ' 1 
Table 3. Experiment 2: Summary of the model fitted to Proportion of fixations to OBJ along $1500 \mathrm{~ms}$ after when offset. Predictors are Time, Pronoun (Null, -0.4 vs. Overt, 0.6), Distribution (Equal, -0.5 vs. Unequal, 0.5 ), and Variety (BP, $-0.5 ; \mathrm{EP}, 0.5)$.

Proportion of fixations to Object

\begin{tabular}{|c|c|c|c|c|}
\hline Predictors & Estimate & SE & t-value & p-value \\
\hline (Intercept) & 0.24 & 0.02 & 15.03 & $<.01$ \\
\hline distribution [Equal,-0.5; Unequal, 0.5 ] & 0.03 & 0.03 & 1.05 & 0.29 \\
\hline pronoun $[\mathrm{N},-0.4 ; 0,0.6]$ & 0.06 & 0.02 & 2.48 & 0.01 \\
\hline Time & 0.01 & 0.01 & 4.89 & $<.01$ \\
\hline variety $[\mathrm{BP},-0.5 ; \mathrm{EP}, 0.5]$ & 0.01 & 0.03 & 0.02 & 0.98 \\
\hline distribution:pronoun & 0.04 & 0.04 & 1.07 & 0.29 \\
\hline distribution:Time & 0.01 & 0.01 & 1.36 & 0.17 \\
\hline pronoun:Time & 0.01 & 0.01 & 5.31 & $<.01$ \\
\hline distribution:variety & 0.02 & 0.05 & 0.44 & 0.66 \\
\hline pronoun:variety & -0.02 & 0.04 & -0.44 & 0.66 \\
\hline Time:variety & -0.01 & 0.01 & -2.08 & 0.04 \\
\hline distribution:Time:variety & -0.01 & 0.01 & -2.03 & 0.04 \\
\hline pronoun:Time:variety & -0.01 & 0.01 & -4.17 & $<.01$ \\
\hline distribution:pronoun:variety & -0.05 & 0.07 & -0.73 & 0.46 \\
\hline distribution:pronoun:Time & 0.01 & 0.01 & 8.29 & $<.01$ \\
\hline distribution:pronoun:Time:variety & -0.01 & 0.01 & -2.72 & 0.01 \\
\hline
\end{tabular}


Table 4. Experiment 2: Summary of the model fitted to Mean Proportion of fixations to Object. Predictors are Pronoun (Null, -0.4 vs. Overt, 0.6), Distribution (Equal, -0.5 vs. Unequal, 0.5$)$, Variety (BP, $-0.5 ; \mathrm{EP}, 0.5)$ and POvert (-0.37 to 0.63$)$.

\section{Mean Proportion of fixations to Object}

\begin{tabular}{|c|c|c|c|c|}
\hline Predictors & Estimate & SE & t-value & p-value \\
\hline (Intercept) & 0.25 & 0.02 & 14.30 & $<.01$ \\
\hline pronoun $[\mathrm{N},-0.4 ; 0,0.6]$ & 0.05 & $\mathbf{0 . 0 3}$ & 1.90 & 0.06 \\
\hline variety $[\mathrm{BP},-0.5 ; \mathrm{EP}, 0.5]$ & 0.02 & 0.03 & 0.79 & 0.43 \\
\hline distribution [Equal,-0.5; Unequal, 0.5] & 0.03 & 0.03 & 0.84 & 0.40 \\
\hline POvert & 0.01 & 0.06 & 0.18 & 0.86 \\
\hline pronoun:POvert & -0.12 & 0.13 & -0.90 & 0.37 \\
\hline variety:POvert & 0.24 & 0.12 & 1.97 & 0.05 \\
\hline distribution:POvert & 0.08 & 0.12 & 0.65 & 0.52 \\
\hline pronoun:variety & 0.01 & 0.05 & 0.15 & 0.88 \\
\hline pronoun:distribution & 0.00 & 0.05 & -0.03 & 0.98 \\
\hline variety:distribution & 0.09 & 0.06 & 1.52 & 0.13 \\
\hline pronoun:variety:POvert & 0.30 & 0.26 & 1.14 & 0.26 \\
\hline pronoun:distribution:POvert & -0.12 & 0.26 & -0.46 & 0.65 \\
\hline variety:distribution:POvert & 0.24 & 0.25 & 0.95 & 0.34 \\
\hline pronoun:variety:distribution & 0.06 & 0.10 & 0.56 & 0.58 \\
\hline pronoun:variety:distribution:POvert & 0.09 & 0.53 & 0.18 & 0.86 \\
\hline
\end{tabular}


Table B1: Experiment 2: Summary of the model fitted to Proportion of fixations to SUBJ along $1500 \mathrm{~ms}$ after when offset. Predictors are Time (Linear, Time1, Quadratic, Time2), Pronoun (Null, -0.4 vs. Overt, 0.6), Distribution (Equal, -0.5 vs. Unequal, 0.5 ), and Variety $(\mathrm{BP},-0.5 ; \mathrm{EP}, 0.5)$

\section{Proportion of fixations to Subject}

\begin{tabular}{|c|c|c|c|c|}
\hline Predictors & Estimate & $\mathrm{SE}$ & t-value & p-value \\
\hline (Intercept) & 0.23 & 0.02 & 15.24 & $<.01$ \\
\hline distribution [Equal, -0.5 ; Unequal, 0.5 ] & 0.02 & 0.03 & 0.85 & 0.40 \\
\hline pronoun $[\mathrm{N},-0.4 ; 0,0.6]$ & -0.05 & 0.02 & -2.92 & $<.01$ \\
\hline Time1 & 0.01 & 0.01 & -0.25 & 0.81 \\
\hline Time2 & 0.01 & 0.01 & 0.07 & 0.95 \\
\hline variety $[\mathrm{BP},-0.5 ; \mathrm{EP}, 0.5]$ & -0.03 & 0.03 & -1.21 & 0.23 \\
\hline distribution:pronoun & 0.01 & 0.03 & 0.11 & 0.91 \\
\hline distribution:Time1 & 0.01 & 0.02 & 0.06 & 0.95 \\
\hline pronoun:Time1 & -0.01 & 0.02 & -0.35 & 0.73 \\
\hline distribution:variety & -0.03 & 0.05 & -0.57 & 0.57 \\
\hline pronoun:variety & -0.01 & 0.03 & -0.26 & 0.79 \\
\hline Time1:variety & 0.01 & 0.02 & 0.38 & 0.70 \\
\hline Time2:variety & 0.01 & 0.02 & 0.18 & 0.86 \\
\hline distribution:Time2 & 0.01 & 0.02 & 0.12 & 0.91 \\
\hline pronoun:Time2 & 0.01 & 0.02 & 0.18 & 0.86 \\
\hline distribution:Time1:variety & 0.01 & 0.04 & 0.07 & 0.94 \\
\hline distribution:Time2:variety & -0.01 & 0.04 & -0.25 & 0.80 \\
\hline
\end{tabular}


ADAPTATION IN PRONOUN RESOLUTION

\begin{tabular}{lcccc}
\hline pronoun:Time1:variety & -0.01 & 0.04 & -0.34 & 0.74 \\
\hline pronoun:Time2:variety & -0.01 & 0.04 & -0.23 & 0.82 \\
\hline distribution:pronoun:variety & 0.01 & 0.05 & 0.25 & 0.80 \\
\hline distribution:pronoun:Time1 & -0.03 & 0.04 & -0.72 & 0.47 \\
\hline distribution:pronoun:Time2 & 0.01 & 0.04 & -0.05 & 0.96 \\
\hline distribution:pronoun:Time1:variety & 0.01 & 0.09 & 0.04 & 0.97 \\
\hline
\end{tabular}


Table B2. Experiment 2: Summary of the model fitted to mean Proportion of fixations to SUBJ. Predictors are Pronoun (Null, -0.4 vs. Overt, 0.6), Distribution (Equal, -0.5 vs. Unequal, 0.5$)$, and Variety (BP, $-0.5 ; \mathrm{EP}, 0.5)$, and POvert (-0.37 to 0.63$)$.

\begin{tabular}{|c|c|c|c|c|}
\hline \multicolumn{5}{|c|}{ Mean Proportion of fixations to Subject } \\
\hline Predictors & Estimate & $\mathrm{SE}$ & t-value & p-value \\
\hline (Intercept) & 0.22 & 0.02 & 12.95 & $<.01$ \\
\hline pronoun $[\mathrm{N},-0.4 ; \mathrm{O}, 0.6]$ & -0.04 & 0.02 & -1.56 & 0.12 \\
\hline variety $[\mathrm{BP},-0.5 ; \mathrm{EP}, 0.5]$ & -0.05 & 0.03 & -1.54 & 0.12 \\
\hline distribution [Equal, $-0.5 ;$ Unequal, 0.5 ] & 0.05 & 0.03 & 1.43 & 0.15 \\
\hline POvert & 0.06 & 0.07 & 0.95 & 0.34 \\
\hline pronoun:POvert & 0.10 & 0.13 & 0.75 & 0.45 \\
\hline variety:POvert & 0.02 & 0.13 & 0.17 & 0.86 \\
\hline distribution:POvert & -0.21 & 0.13 & -1.70 & 0.09 \\
\hline pronoun:variety & 0.04 & 0.05 & 0.79 & 0.43 \\
\hline pronoun:distribution & 0.02 & 0.05 & 0.33 & 0.74 \\
\hline variety:distribution & 0.01 & 0.06 & -0.06 & 0.95 \\
\hline pronoun:variety:POvert & 0.10 & 0.25 & 0.39 & 0.70 \\
\hline pronoun:distribution:POvert & 0.14 & 0.26 & 0.55 & 0.58 \\
\hline variety:distribution:POvert & -0.24 & 0.25 & -0.96 & 0.34 \\
\hline pronoun:variety:distribution & 0.02 & 0.10 & 0.19 & 0.85 \\
\hline pronoun:variety:distribution:POvert & 0.60 & 0.51 & 1.18 & 0.24 \\
\hline
\end{tabular}




\section{Figures}

\section{Constant resolution biases}

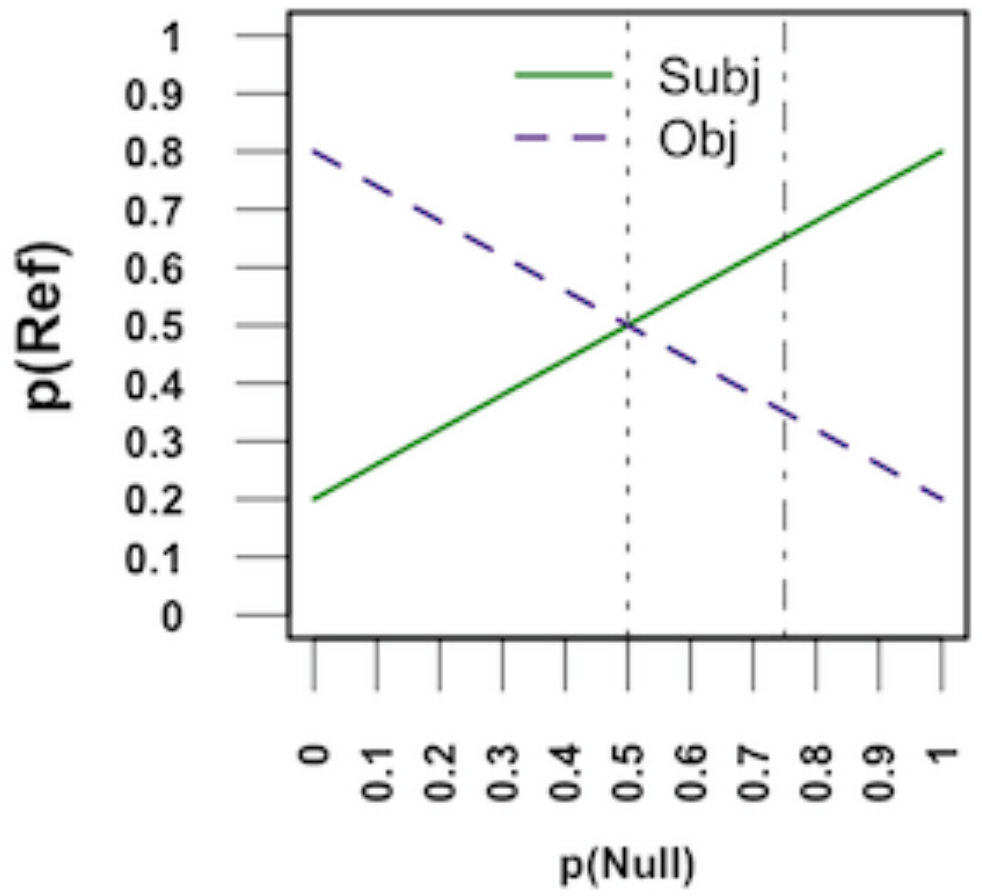

Figure 1. Illustration of the relationship between the probabilities of Referents ( $p(\mathrm{Subj})$ and $\mathrm{p}(\mathrm{Obj}))$ and changes in pronoun probability, while keeping resolution biases constant $(\mathrm{p}($ Subj $\mid$ Null $)=0.8 ; \mathrm{p}($ Obj $\mid$ Null $)=0.2 ; \mathrm{p}($ Obj $\mid$ Overt $)=0.8 ; \mathrm{p}($ Subj $\mid$ Overt $)=0.2)$. Vertical lines indicate the statistical environments where null and overt pronouns are equally $(0.5 / 0.5)$ and unequally (0.75/0.25) distributed (dotted and dotdash lines). 

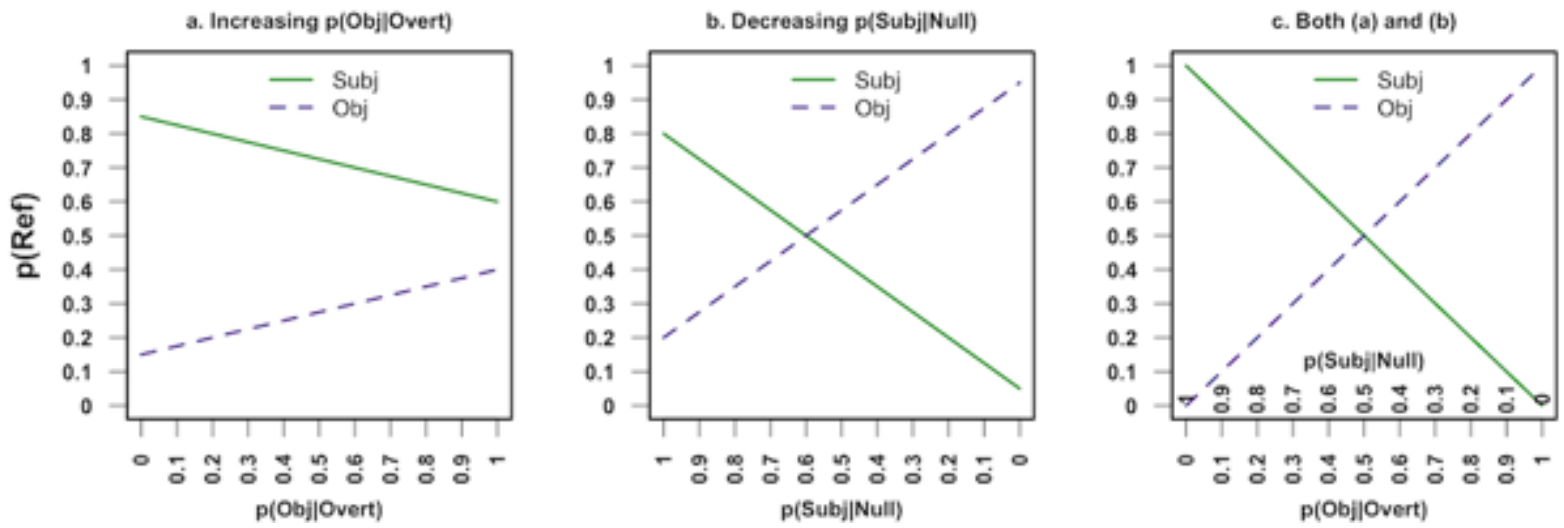

Figure 2. Illustration of the relationship between the probabilities of Referents ( $p(\operatorname{Subj})$ and $\mathrm{p}(\mathrm{Obj}))$ and changes in resolution biases, in a statistical environment where null and overt pronouns have probabilities of 0.75 and 0.25 , respectively: The probability of Object increases, and the probability of Subject decreases when $\mathrm{p}(\mathrm{Obj} \mid \mathrm{Overt})$ increases (a), $\mathrm{p}($ Subj $\mid$ Null $)$ decreases (b), or both $\mathrm{p}(\mathrm{Obj} \mid$ Overt $)$ increases and $\mathrm{p}(\mathrm{Subj} \mid \mathrm{Null})$ decreases (c). 
Equal Distribution

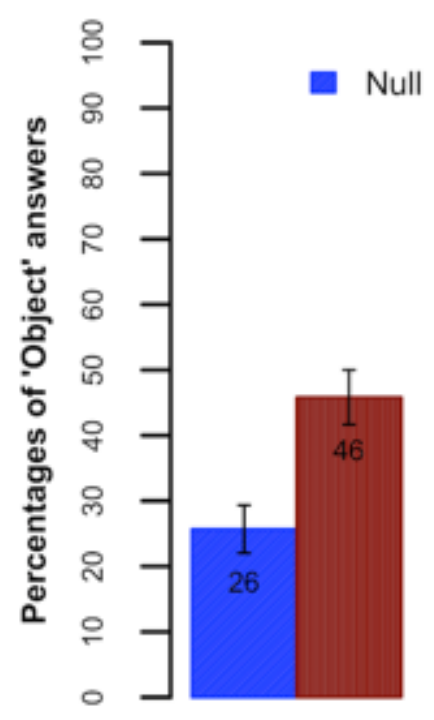

BP

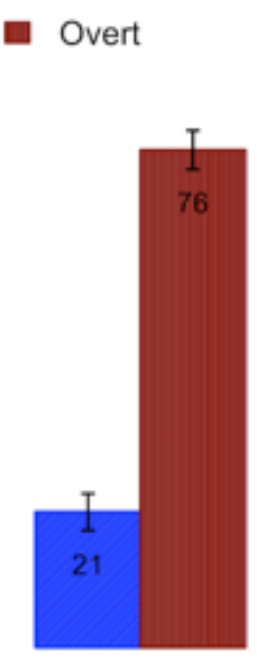

EP
Unequal Distribution

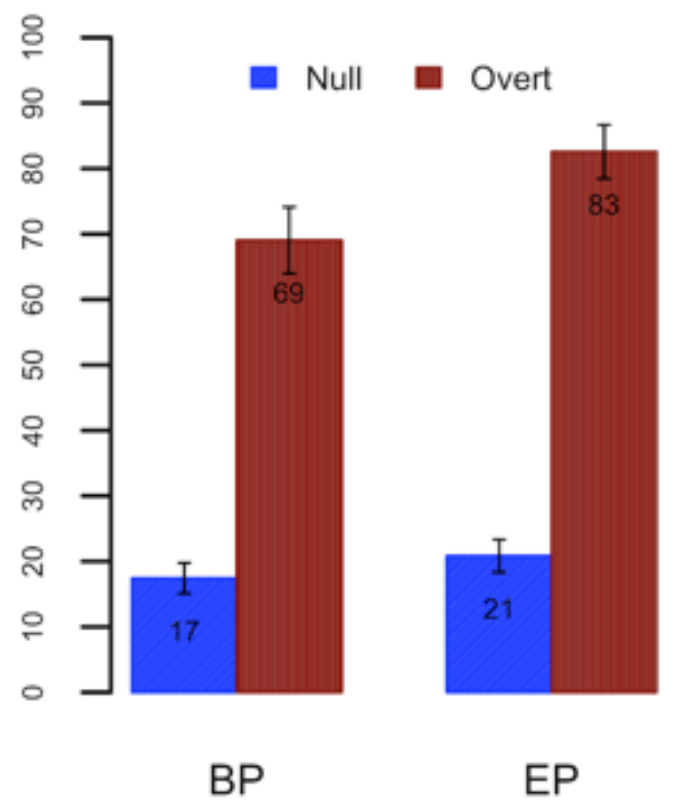

Figure 3. Experiment 1; Mean percentage of 'object' responses in BP and EP for the conditions crossing Pronoun (Null, blue bars vs. Overt, red bars) and Distribution (Equal, left panel vs. Unequal, right panel). Arrows represent SEs around the observed means. 

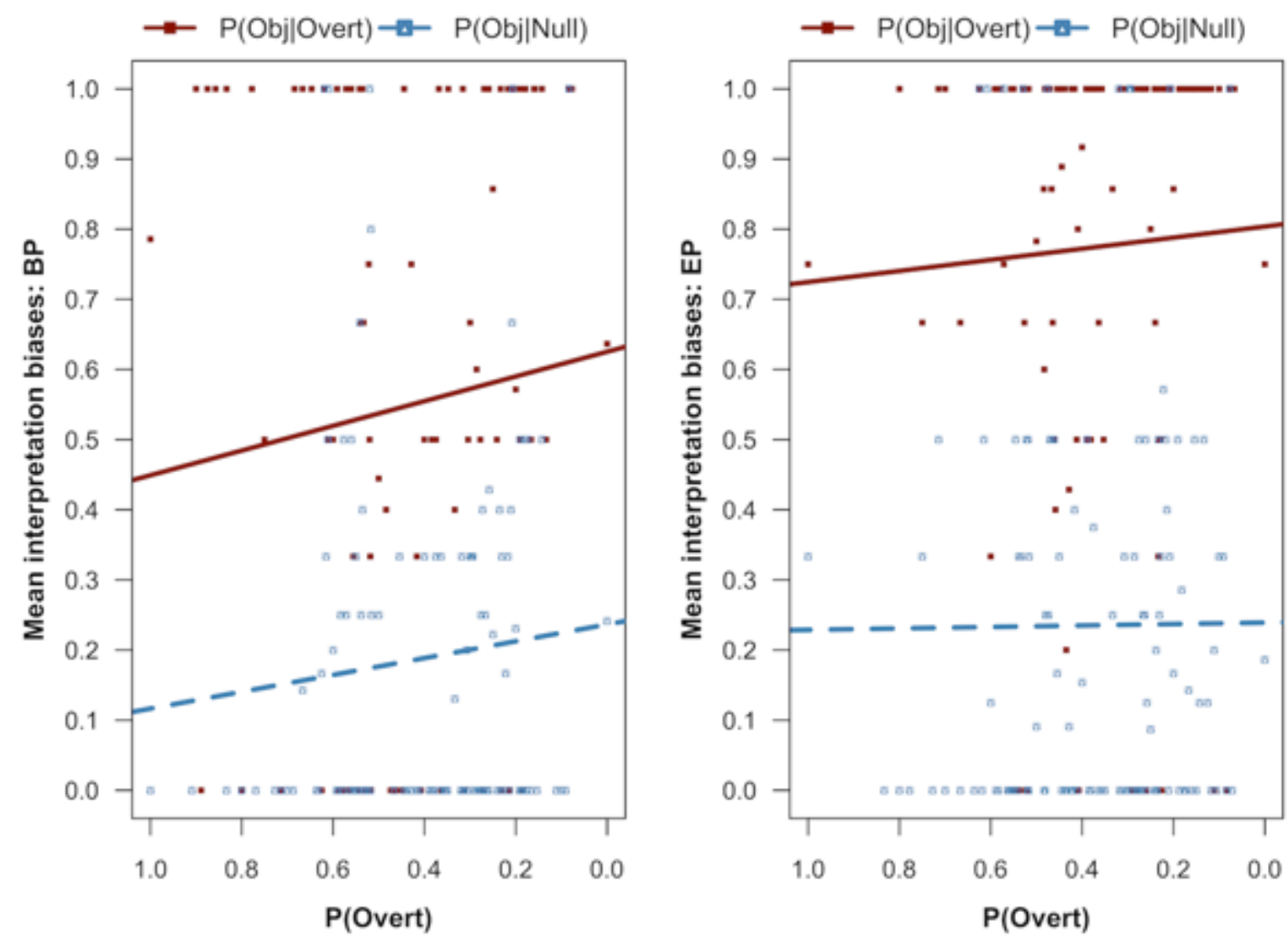

Figure 4. Experiment 1; Mean probabilities of selecting object referents given overt and null pronouns, for each value POvert, for BP (left panel) and EP (right panel). The x-scale is reversed for purposes of easier interpretation. 


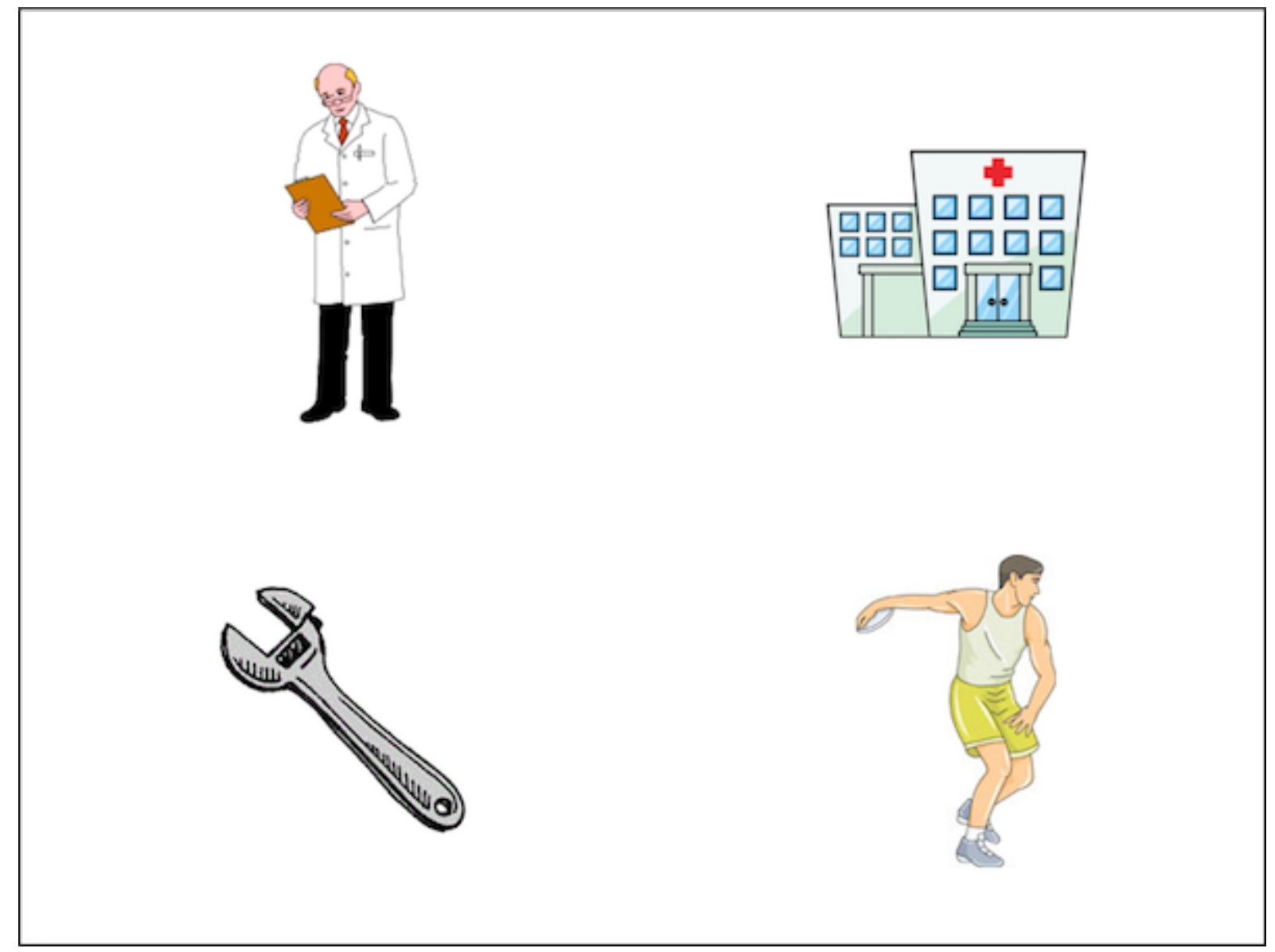

Figure 5. Visual context depicting the entities mentioned in the spoken target sentence The athlete consulted the orthopaedist at the hospital when he/ Ø returned form the journey to Italy: the pronoun antecedents (subject: ATHLETE and object: ORTHOPAEDIST), the location (HOSPITAL) and the distractor (SCREWDRIVER). 
a. Equal distribution BP



c. Equal distribution EP

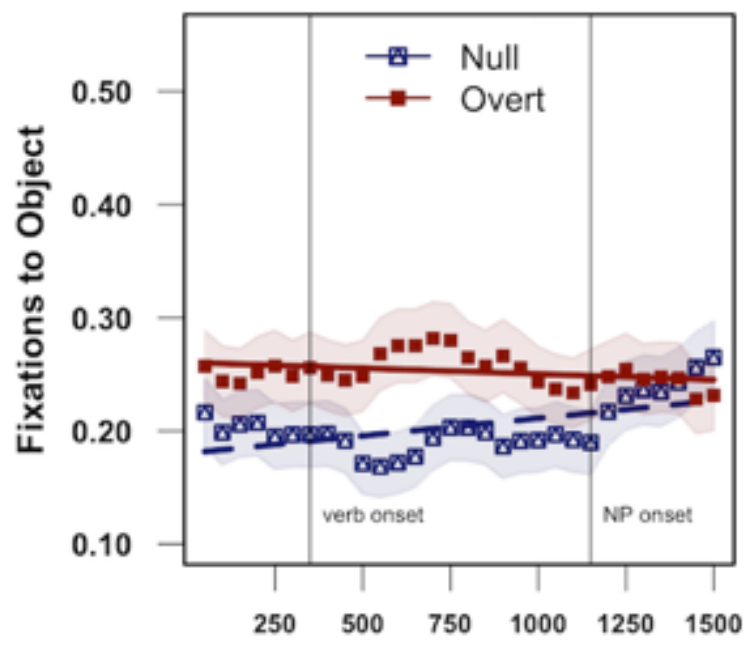

Time course from 'when' offset b. Unequal distribution BP

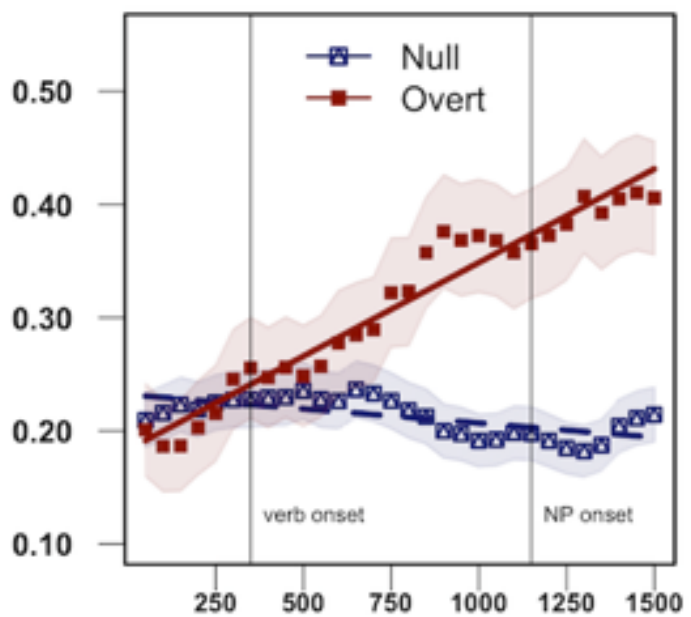

d. Unequal distribution EP

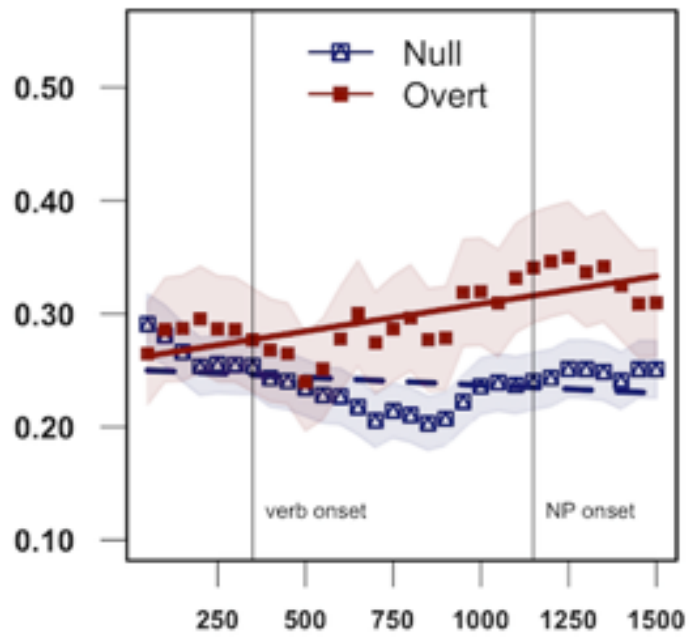

Time course from 'when' offset

Figure 6. Experiment 2; Time-course of proportion of fixation to OBJ from the offset of when for BP (top row) and EP (bottom row) in the conditions crossing Pronoun (Null, blue vs.

Overt, red) and Distribution (Equal, left panels vs. Unequal, right panels). Observed data are plotted as symbols (Null, square and triangle up vs. Overt, filled square), whereas lines (Null, dashed vs. Overt, solid) correspond to the model fits. Shaded bands represent SEs around the observed means. The vertical lines indicate the mean onsets of the verb and of the following phrase. 

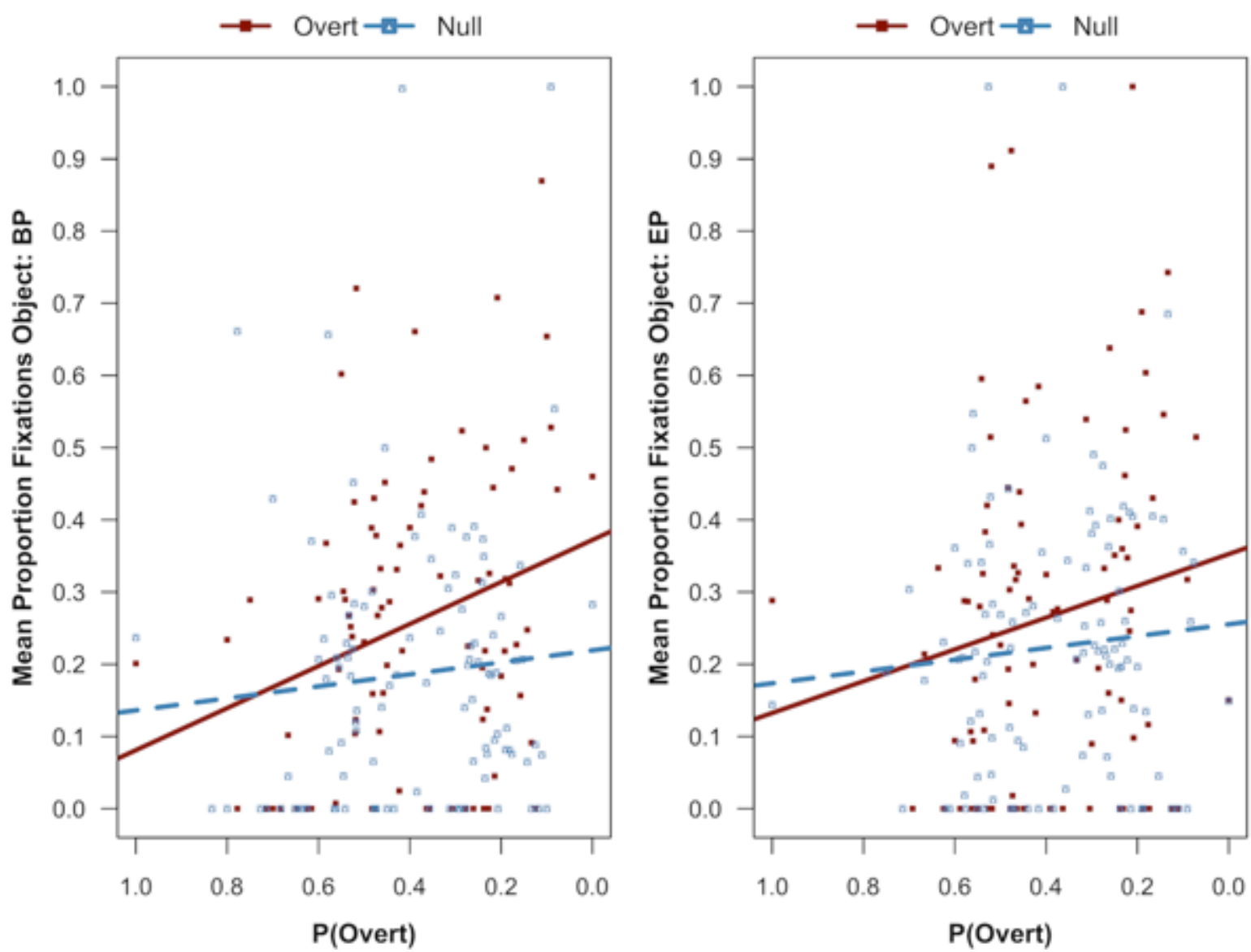

Figure 7. Experiment 2; Mean fixation to OBJ as a function of $\mathrm{P}(\mathrm{Overt})$ for $\mathrm{BP}$ (left) EP (right) for Null (blue lines) and Overt (red lines) pronouns. 


\section{a. Equal distribution BP}



c. Equal distribution EP

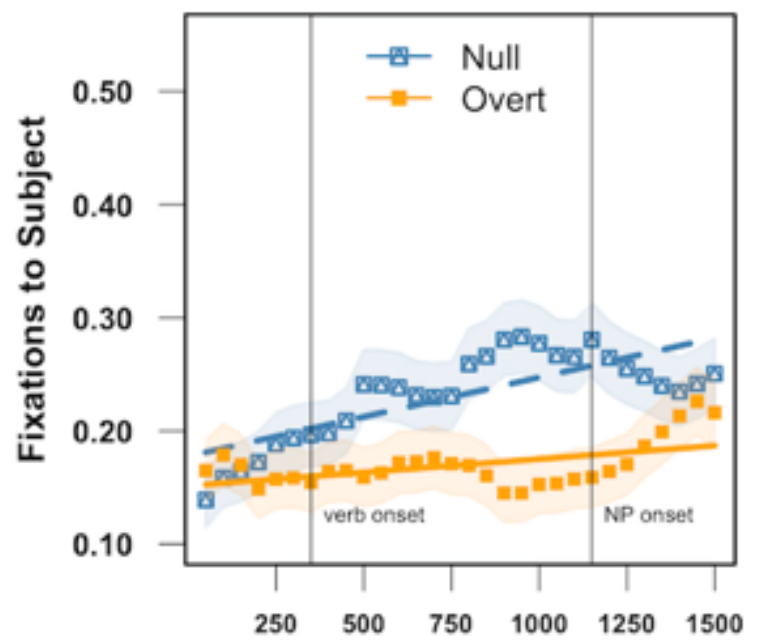

Time course from 'when' offset b. Unequal distribution BP

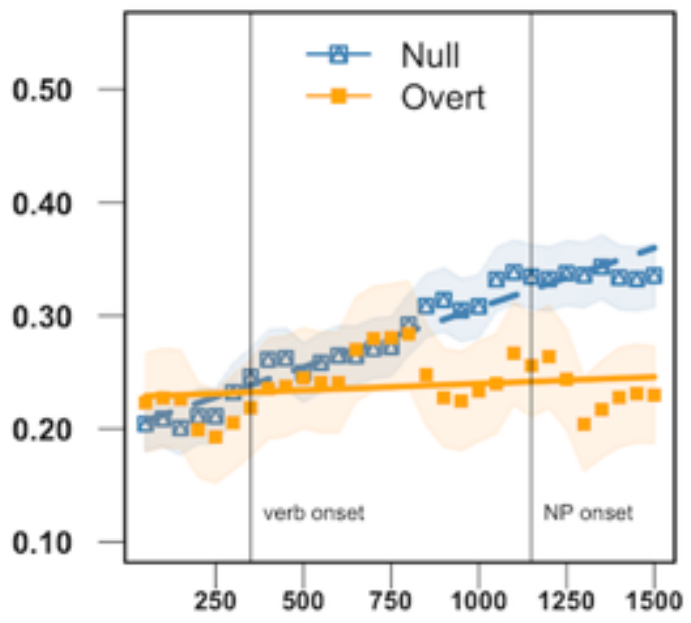

d. Unequal distribution EP

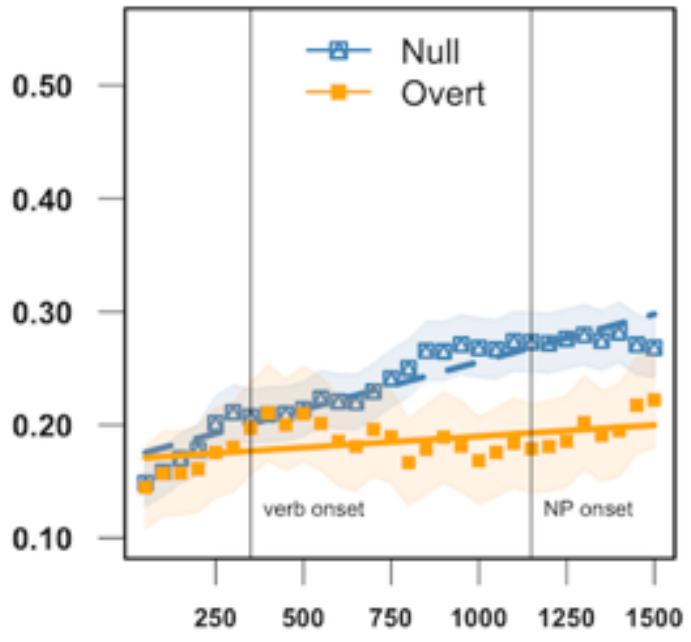

Time course from 'when' offset

Figure B1. Experiment 2; Time-course of proportion of fixation to SUBJ from the offset of when for BP (top row) and EP (bottom row) in the conditions crossing Pronoun (Null, blue vs. Overt, orange) and Distribution (Equal, left panels vs. Unequal, right panels). Observed data are plotted as symbols (Null, square and triangle up vs. Overt, filled square), whereas lines (Null, dashed vs. Overt, solid) correspond to the model fits. Shaded bands represent SEs around the observed means. The vertical lines indicate the mean onsets of the verb and of the following phrase. 

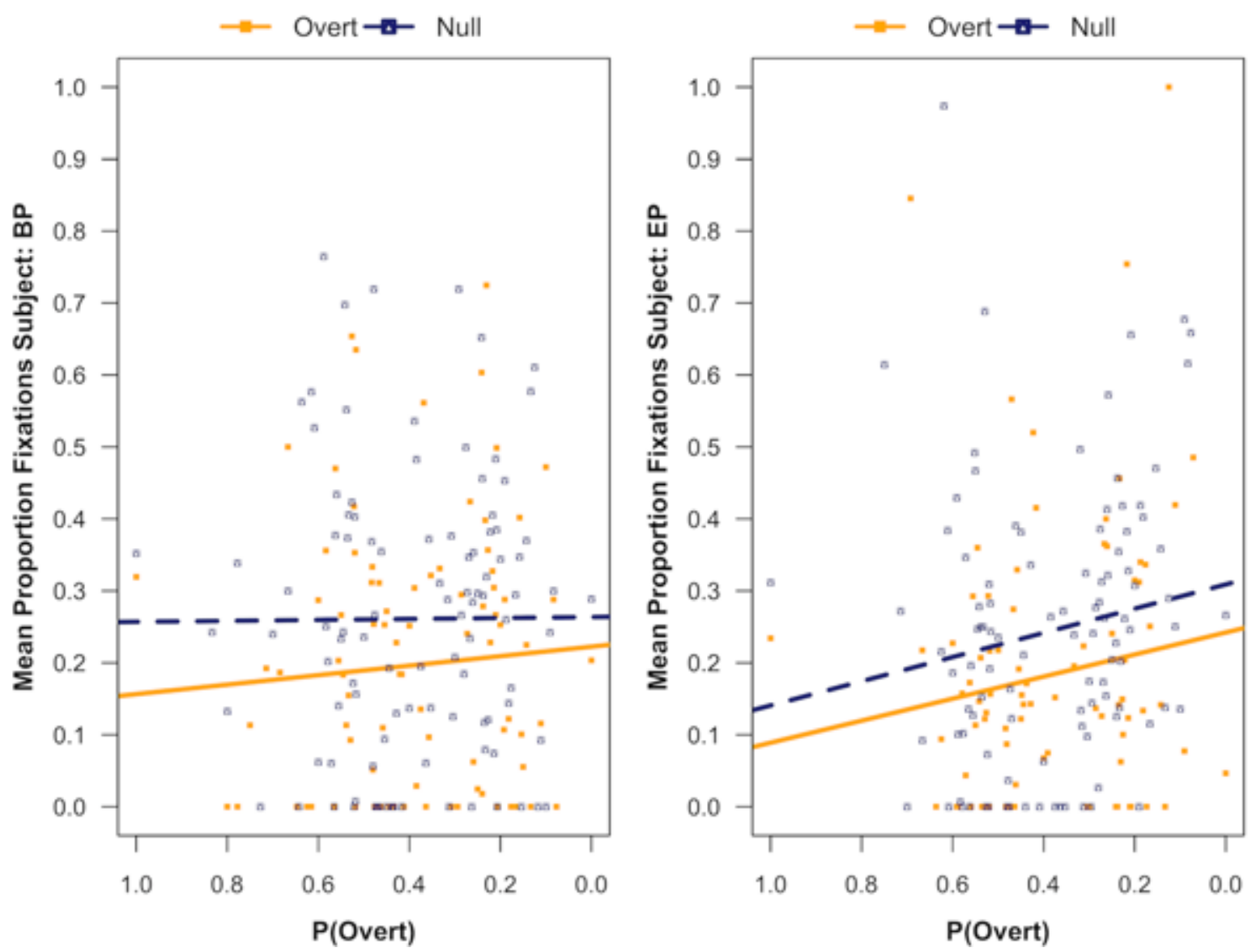

Figure B2. Experiment 2; Mean fixation to SUBJ as a function of $\mathrm{P}(\mathrm{Overt})$ for BP (left) EP (right) for Null (blue lines) and Overt (red lines) pronouns. 
End notes

We use the term anaphoric expression/ form to refer broadly to referential expressions such as pronouns, nouns or demonstratives. For a pronoun, the inflected forms such as $s / h e$ are considered to be the same anaphoric expression.

ii Other factors that have been identified as contributing to the prominence of referents are, for example, accessibility in memory (Ariel, 1990, 1994), the degree of focus (Garrod \& Sanford, 1982), or informational status (giveness, Gundel, Hedberg, \& Zacharski, 1993). We will not focus on these, but we note that they might be explained by/ associated with probability of entities: For example, a more frequent referent is arguably more likely focused in the discourse.

iii Importantly, since we are not concerned with semantic biases, we controlled as much as possible for the effects driven by the referents likelihood, by using verbs that were identified as not inducing a bias neither for NP1 or NP2 continuations. In particular, we used Agent-Patient verbs that have been shown to be equi-biased in Portuguese (Costa, Faria, \& Kail, 2004). Moreover, the semantic roles of agent and patient did not vary across grammatical condition (i.e., the agent-patient order corresponded always to the subject-object order).

iv Note that the evidence from corpora studies is somehow restricted, and variable as to the exact relative frequencies of these two pronominal forms in the two varieties. For the case of ambiguous third person subjects, the percentages of null and overt pronouns have been established, respectively, around $80 \%$ vs. $20 \%$, for EP, and $40 \%$ vs. $60 \%$, for BP (Barbosa, Duarte, \& Kato, 2005). It is generally agreed, however, that BP displays an increased use of overt pronouns in contexts where a null pronoun would occur in EP (e.g., Duarte, 2000; but see Almor, Carvalho Maia, Lima, Vernice, $\&$ Gelormini-Lezama, 2017, and references therein).

$\checkmark \quad$ In order for all items to appear in the overt pronoun condition of the unequal distribution lists (in which only eight out of 32 items had the overt pronoun), we created four lists for the unequal distribution condition and duplicated the two equal distribution condition lists, so as to have eight lists across which the participants were randomly distributed.

vi $\quad \mathrm{p}($ Null), the probability of a Null pronoun, is, for each value of POvert $\mathrm{p}, 1-\mathrm{p}$.

vii The mean percentage of subject answers in the null pronoun condition, however, is higher in the unequal, relative to equal, distribution condition (see Figure 1). This most likely reflects the lower sensitivity of an analysis that averages the outcomes from a range of different values of POvert. In contrast, POvert captures small and constant variations in pronoun probability that can be observed in both distribution conditions.

viii As pointed out by an anonymous reviewer, the fact that, in the null pronoun condition, the first evidence of the existence of the null pronoun comes at the verb, can raise the question of the appropriate alignment between conditions. We conducted further analyses where, for the null pronoun condition, we considered data from $150 \mathrm{~ms}$ after when offset, corresponding roughly to verb onset in this condition (more precisely, $150 \mathrm{~ms}$ is the difference between the mean when offset and the mean verb onset in this condition). We considered a $1500 \mathrm{~ms}$ time window starting here, and compared it 
with the 1500 time window of the overt pronoun condition (aligned to when offset). Crucially, the relevant effects remain significant in this new analysis: For the analysis of proportion of fixations to OBJ, main effect of pronoun, interaction Pronoun:Time and interaction Pronoun:Variety:Distribution:Time; For the analysis of proportion of fixations to SUBJ, main effect of pronoun, interaction between Pronoun and Time, and three-way interaction Pronoun:Time:Variety.

ix We ran two other models including higher order terms of Time, a quadratic model (including Time $^{2}$ ) and a cubic model ( Time $^{2}$ and Time ${ }^{3}$ ), but found no evidence that adding either the $2^{\text {nd }}$ or the $3^{\text {rd }}$ terms improved the fit of the model with only a $1^{\text {st }}$ order Time term, as indicated by likelihood ratio tests (assessing changes in deviance (-2LL), all non-significant, for both the data on fixations to Object and for the data on fixations to Subject). We therefore present the simpler linear models.

$x \quad$ Having relatively many observations, the t-distribution converges to the $\mathrm{z}$-distribution, and so a normal approximation is used: coefs $\$ p=$ format.pval $(2 *(1-$ pnorm $(\operatorname{abs}(\operatorname{coefs} \$ t$.value $)))$, digits $=2$, eps $=0.0001$ ), in R syntax.

xi Prior work showed that the strength of the interpretation bias of the French overt pronoun $i l$ is reliably different when only that form is presented in the experimental context and when it is presented alongside the stressed form of the pronoun, lui , il (Colonna, Schimke, Vincent, de la Fuente, \& Hemforth, 2016; see also de la Fuente \& Hemforth, 2013), thus supporting this hypothesis. However, such results were not interpreted under the probabilistic or adaptation framework we are considering currently.

xii We tried to collect information about residence length from all participants, but that information is missing for 11 participants (six EP speakers and five BP speakers). From the 37 participants from whom we got this information, only two were living in France since longer than three years. 